\title{
Multiresolution analysis of the spatiotemporal variability in global radiation observed by a dense network of 99 pyranometers
}

\author{
Bomidi Lakshmi Madhavan ${ }^{1, a}$, Hartwig Deneke ${ }^{1}$, Jonas Witthuhn ${ }^{1}$, and Andreas Macke ${ }^{1}$ \\ ${ }^{1}$ Leibniz-Institute for Tropospheric Research (TROPOS), Permoserstraße 15, 04318 Leipzig, Germany \\ ${ }^{a}$ now at: Department of Marine Sciences, Goa University, Goa 403 206, India \\ Correspondence to: Bomidi Lakshmi Madhavan (madhavan.bomidi@ tropos.de, blmadhavan@gmail.com)
}

Received: 1 August 2016 - Discussion started: 8 November 2016

Revised: 14 February 2017 - Accepted: 14 February 2017 - Published: 8 March 2017

\begin{abstract}
The time series of global radiation observed by a dense network of 99 autonomous pyranometers during the HOPE campaign around Jülich, Germany, are investigated with a multiresolution analysis based on the maximum overlap discrete wavelet transform and the Haar wavelet. For different sky conditions, typical wavelet power spectra are calculated to quantify the timescale dependence of variability in global transmittance. Distinctly higher variability is observed at all frequencies in the power spectra of global transmittance under broken-cloud conditions compared to clear, cirrus, or overcast skies. The spatial autocorrelation function including its frequency dependence is determined to quantify the degree of similarity of two time series measurements as a function of their spatial separation. Distances ranging from $100 \mathrm{~m}$ to $10 \mathrm{~km}$ are considered, and a rapid decrease of the autocorrelation function is found with increasing frequency and distance. For frequencies above $1 / 3 \mathrm{~min}^{-1}$ and points separated by more than $1 \mathrm{~km}$, variations in transmittance become completely uncorrelated. A method is introduced to estimate the deviation between a point measurement and a spatially averaged value for a surrounding domain, which takes into account domain size and averaging period, and is used to explore the representativeness of a single pyranometer observation for its surrounding region. Two distinct mechanisms are identified, which limit the representativeness; on the one hand, spatial averaging reduces variability and thus modifies the shape of the power spectrum. On the other hand, the correlation of variations of the spatially averaged field and a point measurement decreases rapidly with increasing temporal frequency. For a grid box of $10 \mathrm{~km} \times 10 \mathrm{~km}$ and averaging periods of $1.5-3 \mathrm{~h}$, the deviation of global transmittance between a point measurement
\end{abstract}

and an area-averaged value depends on the prevailing sky conditions: 2.8 (clear), 1.8 (cirrus), 1.5 (overcast), and $4.2 \%$ (broken clouds). The solar global radiation observed at a single station is found to deviate from the spatial average by as much as 14-23 (clear), 8-26 (cirrus), 4-23 (overcast), and $31-79 \mathrm{~W} \mathrm{~m}^{-2}$ (broken clouds) from domain averages ranging from $1 \mathrm{~km} \times 1 \mathrm{~km}$ to $10 \mathrm{~km} \times 10 \mathrm{~km}$ in area.

\section{Introduction}

The Sun is the primary source of energy for the Earth's climate system. Clouds strongly modulate the radiation budget through reflection of solar radiation back to space, and by trapping terrestrial radiation within the atmosphere (Trenberth et al., 2009). A better understanding of the small-scale variability in the radiation field at the surface resulting from clouds will have numerous practical applications, ranging from climate-related research focused on cloud radiative effects and cloud-aerosol interactions, representing of radiative transfer in numerical weather prediction (van den Hurk et al., 1997) and to solar energy forecasting (Robles Gil, 2007). According to the latest Intergovernmental Panel on Climate Change report, the impact of various cloud types on the net radiation budget is not fully understood to the extent that for some cloud types neither the magnitude nor even the sign is known (Boucher et al., 2013).

This can be attributed to our currently still very limited understanding of cloud processes and the resulting cloudradiation interactions, due to their complexity and the wide range of scales involved. Small-scale processes such as updraughts and downdraughts, turbulent mixing, as well as the 
availability and composition of cloud condensation nuclei and large-scale dynamics, influence the formation and life cycle of clouds, which subsequently determine their optical properties and thus their interaction with radiation (e.g., Baker, 1997; Scheirer and Macke, 2003; Baker and Peter, 2008). Consequently, clouds induce the largest amount of uncertainty in climate projections (Baker and Peter, 2008) and weather prediction (Stensrud, 2009).

Satellite observations are one very important source of information for investigating clouds and their radiative effects. Current operational retrievals of cloud properties from passive satellite sensors do however invoke the assumption of plane-parallel, horizontally homogeneous clouds. While these retrievals have been extensively evaluated with groundbased measurements over the past years (e.g., Roebeling et al., 2008; Madhavan et al., 2012; Stubenrauch et al., 2013; Norris and Evan, 2015; Enriquez-Alonso et al., 2016), significant biases and uncertainties remain due to the limitations of this assumption (e.g., Horvath et al., 2014).

These complications can be mainly attributed to horizontal photon transport, radiative smoothing, and sub-pixel inhomogeneity (e.g., Cahalan et al., 1994; Barker and Li, 1997). To address these issues, Pincus et al. (1999) proposed a parameterization to account for unresolved sub-grid-scale variability, which does however depend on a priori information about typical variability for different cloud types. They also identified an increase in optical thickness and a decrease in relative variability in the transition from cumuliform to stratiform clouds. Oreopoulos et al. (2000) studied power spectra obtained from high-resolution Landsat observations, and identified different behavior for scales below $1 \mathrm{~km}$ and within the interval from 1 to $5 \mathrm{~km}$ as a consequence of both cloud morphology and three-dimensional (3-D) cloud radiative effects. Based on a large ensemble of 3-D cloud fields as input for 3-D radiative transfer models, Schewski and Macke (2003) reported that spatially transmitted solar radiation and domain average cloud properties are highly correlated. In related research, Venema et al. (2006) and Schmidt et al. (2007) showed that a stochastic cloud generator together with a 3$D$ radiative transfer model can be used to link the statistical properties of cloud observations to those of the resulting solar radiation field with satisfactory accuracy.

The attribution of deviations between ground-based observations, satellite observations, and model results is also complicated by the effects of spatial collocation and the limited representativeness of a point measurement for domain averages implicitly assumed in any such comparisons (e.g., Deneke et al., 2009; Schutgens and Roebeling, 2009; Greuell and Roebeling, 2009). Large inconsistencies are expected to occur in particular for short time periods $(<1 \mathrm{~h})$ and brokencloud fields, if point measurements are compared to large satellite pixels or coarse-resolution model output $(>1 \mathrm{~km})$.

Focusing on solar radiation, Núñez et al. (2005) concluded that for stratocumulus clouds, a high frequency of observations is required to estimate the hourly averaged global radia- tion from satellites with acceptable accuracy $(\sim 5 \%$ error for six scans per hour). To estimate the representativeness of a point measurement for a larger domain, Long and Ackerman (1995) used data from a network of pyranometers during the First International Satellite Cloud Climatology Project Regional Experiment, and showed that a spatial separation between the measurement sites of up to $150 \mathrm{~km}$ can be allowed for daily averages. This is, however, mainly attributable to the fact that correlation is dominated by the diurnal cycle of solar radiation at the top of atmosphere. In another study, Barnett et al. (1998) found a characteristic timescale of $60 \mathrm{~min}$ for solar radiation on cloudless days, and twice that long for cloudy days, after removal of the diurnal cycle component. They also concluded that to achieve a correlation of 0.9 between measurements at a point and averaged over a surrounding area on cloudy days, the central site can be considered representative for a region with a radius of $30 \mathrm{~km}$. Both Barnett et al. (1998) and Duchon and O'Malley (1999) reported that the representativeness of a point measurement for area averages depends on the considered averaging time and the prevailing cloud type.

Comparing satellite-based solar radiation retrievals from the Advanced Very High-Resolution Radiometer to pyranometer observations, Deneke et al. (2005) reported a large root mean square error (RMSE) of $86 \mathrm{~W} \mathrm{~m}^{-2}$ for individual station records even when averaging over $10 \times 10$ satellite pixels and over $40 \mathrm{~min}$. In contrast, a much better accuracy (RMSE $\sim 33 \mathrm{~W} \mathrm{~m}^{-2}$ ) is achieved if the average of 30 stations is considered. They interpret this finding as evidence that a significant fraction of the RMSE in the comparison results from the variability of the global radiation field due to the limited representativeness of the pyranometer measurements for the satellite-retrieved values.

Over the past decades, several ground-based surface radiation networks have been established (e.g., Barker et al., 1998; Ohmura et al., 1998; Michalsky et al., 1999). However, a dense network of solar radiation measurements at the surface with station distances smaller than a typical satellite pixel or model grid has to our knowledge not been realized before. Such a network has been developed and operated during the High Definition Clouds and Precipitation for advancing Climate Prediction $\left(\mathrm{HD}(\mathrm{CP})^{2}\right)$ Observation Prototype Experiment (HOPE) conducted around Jülich, Germany (Madhavan et al., 2016). This unique data set can provide insights into the small-scale variability of global radiation due to various cloud types, and possibly enable the development of parameterizations of the unresolved spatiotemporal variability in the radiation field. Using this data set, Lohmann et al. (2016) explored the fluctuations of the clear-sky index (i.e., the ratio of instantaneous global radiation to the radiation on the Earth with a cloud-free atmosphere) on clear, overcast, and mixed sky conditions with a simple increment statistics to study the smoothing effects of distributed photovoltaic power production. 
Spatial and temporal scaling properties of the time series of observed global radiation can be derived using a wavelet-based multiresolution analysis. Wavelet-based estimators of variance, covariance, and cross-correlation decompose their scale-independent counterparts on a scale-by-scale basis. Multiple studies have adapted similar wavelet-based methods to explore a wide range of subjects involving the atmospheric time series applications (Whitcher et al., 2000), solar radiation (Deneke et al., 2009), fluctuation analysis of the power generated by photovoltaic plants (Perpiñán et al., 2013), geophysical seismic signal analysis (Grosmann and Morlet, 1984), signal and image processing, and vegetation monitoring.

In our study, the statistical properties inferred from a multiresolution analysis (MRA) of the time series of global radiation are subsequently used to quantify the representativeness of a point measurement for a surrounding domain considering typical domain sizes and different sky conditions. Instead of directly considering the global radiation, its transmission by the atmosphere, denoted as global transmittance is considered in this paper, because the changes in incoming solar radiation are removed at least to first order. The present study is focused at addressing the following research questions:

i. How do the power spectra of global transmittance differ for different sky conditions?

ii. How representative is the time series observed at one station for other nearby stations?

iii. How representative is the single station observation for domain averages considering different spatial- and temporal-averaging scales?

This paper is organized as follows: in Sect. 2 details of the observational data used in this study are presented. An overview of our methods is given in Sect. 3, with more details on the theory given in the Appendix. Section 4 discusses the results of the multiresolution analysis, the behavior of the power spectra, and the spatial correlation under different prevailing sky conditions. These results are further used to investigate the spatial representativeness of a point measurement for spatial averages over typical domain sizes, and to quantify the expected deviations. Finally, the summary and conclusions with an outlook are presented in Sect. 5.

\section{Data sets}

As part of the HOPE campaign, a high-density network of 99 autonomous pyranometer stations was operated across a spatial domain covering $50.85-50.95^{\circ} \mathrm{N}$ and $6.36-6.50^{\circ} \mathrm{E}$ $(\sim 10 \mathrm{~km} \times 12 \mathrm{~km}$ area) around Jülich, Germany, from 2 April to 24 July 2013. Each of these stations continuously recorded the global radiation $\left(G\right.$ in $\left.\mathrm{W} \mathrm{m}^{-2}\right)$ using a silicon photodiode pyranometer (model: EKO ML-020VM)
Table 1. Classification of days into clear, cirrus, overcast, and broken cloudy-sky condition during the HOPE Jülich campaign.

\begin{tabular}{ll}
\hline Sky condition & Observation days (day/month) \\
\hline Clear & 4 May, 8 June, 9 July, 21 July \\
\hline Cirrus & 22 April, 24 April, 16 July \\
\hline Overcast & 9 June, 28 June \\
\hline Broken clouds & 13 April, 25 April, 1 May, 2 May, \\
& 24 May, 4 June, 19 July \\
\hline
\end{tabular}

with $10 \mathrm{~Hz}$ resolution. A Global Positioning System module embedded on the data acquisition board of each station provides an accurate time reference. The global radiation measurements have been averaged into $1 \mathrm{~s}$ time periods during the conversion of the ASCII log files into NetCDF data files following the Climate and Forecast Metadata Conventions version 1.6 (Eaton et al., 2011). From these measurements we have derived the global transmittance $(T)$, which is calculated by normalizing the global radiation $(G)$ under all sky conditions by the extraterrestrial radiation at the top of atmosphere assuming a value of the solar constant of $1360.8 \mathrm{~W} \mathrm{~m}^{-2}$ from Kopp and Lean (2011) and accounting for the cosine of the solar zenith angle and SunEarth distance. The solar zenith angle and the Sun-Earth distance have been calculated following the guidelines of WMO (2008).

The limited spectral range $(0.3-1.1 \mu \mathrm{m})$ of silicon photodiodes is a well-known limitation of this type of pyranometer (King, 1997; Madhavan et al., 2016). Changes in the spectral distribution of downward irradiance compared to the conditions during calibration can lead to errors of up to $5 \%$, particulary at higher solar zenith angles. While the derived global transmittance is sensitive to aerosols and cloud optical thickness, information on cloud thermodynamics phase and cloud droplet effective radius is beyond the spectral range of these silicon photodiode pyranometers. Detailed information about the pyranometer network setup during the HOPE campaign, data processing, quality control, and uncertainty assessment due to various potential sources of error are presented in Madhavan et al. (2016).

The real-time sky conditions were assessed using hemispheric images from a Total Sky Imager (TSI) operated at the Research Center Jülich (FZJ) during the HOPE campaign. Time-azimuth ( $t$-azi) plots were generated from the TSI images. Every line in these $t$-azi plots contains pixels from the azimuth angle range from 0 to $360^{\circ}$, sampled at an elevation angle of $45^{\circ}$. These plots capture both spatial and temporal variability of clouds, and help to identify the dominating advection direction of clouds, which shows up in sine-like patterns (Löhnert et al., 2014). Since the ground-based observations have a field of view, which does not exceed $50 \mathrm{~km}$ in radius (Henderson-Sellers et al., 1987), Meteosat SEVIRI 

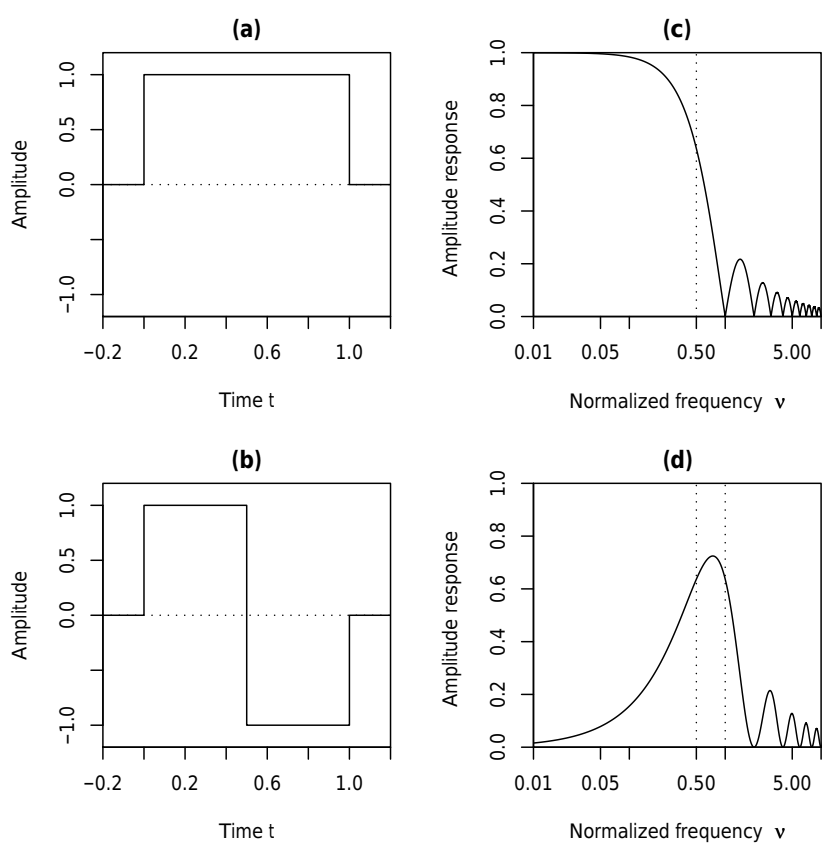

Figure 1. Time representation of the Haar (a) scaling and (b) wavelet function, and the frequency response of the associate (c) low-pass and (d) bandpass filters. Adopted from Deneke et al. (2009).

(Spinning Enhanced Visible and Infrared Imager) images based on the day-natural RGB color composites (Lensky and Rosenfeld, 2008) were additionally used for the physical interpretation and thermodynamic phase identification of the cloud types present over the observation domain. The 0.6, 0.8 , and $1.6 \mu \mathrm{m}$ spectral channels where enhanced in resolution using the high-frequency component of the broadband HRV (high-resolution visible) channel (0.4-1.1 $\mu \mathrm{m}$; Deneke and Roebeling, 2010). Based on the predominant sky conditions during the daylight period (06:00-18:00 h local time), we have classified selected days as clear, cirrus, overcast, or broken cloudy conditions (see Table 1).

\section{Methods}

\subsection{Multiresolution analysis}

A multiresolution analysis (MRA) based on the maximum overlap discrete wavelet transform (MODWT; Percival, 1995) and the Haar wavelet (Haar, 1910) is applied to the time series of global flux transmittance measurements of the pyranometer network. The Haar wavelet filters correspond to rectangular scaling and wavelet functions, which act as low-pass and bandpass filters, respectively (see Fig. 1). Maximum time localization is achieved through the minimal support of the filters. This also minimizes the range of edge effects. The choice of a rectangular function as low-pass filter also has the advantage that it corresponds to an arithmetic average for a specific period and is thus simpler to interpret than the weighted averages obtained by other wavelets. The drawback of the rectangular function as a low-pass filter is its sub-optimal frequency separation, which could result in lower correlations found between time series than those obtained by Gaussian averaging. A summary of the methodology is given here, while a more formal mathematical treatment with relevant references to the literature can be found in the Appendix of Deneke et al. (2009).

In the MRA, the day is chosen as fundamental frequency $f=1$ day $^{-1}$, and the frequency domain is partitioned into bands delimited by the harmonics $f_{J}$ given by $f_{J}=2^{J} \times f$. For obtaining this partitioning, the original data set has been resampled from 86400 to $2^{16}(=65536)$ samples per day before subjecting it to the MRA. To avoid aliasing effects caused by the resampling step, a 3 s running mean has been applied as low-pass filter prior to subsequent decimation of samples by a factor of $\frac{512}{675}$. Only harmonics from $J=3$ to $J=14$ with corresponding averaging time periods of $3 \mathrm{~h}$ $\left(=2^{13}\right.$ samples $)$ and $5.25 \mathrm{~s}\left(=2^{2}\right.$ samples $)$ are considered in the following analyses, avoiding the influence of changes in solar zenith angle below $75^{\circ}$ and the anti-aliasing filter above this frequency range, respectively. The running means of the original time series for the different harmonics $J$ (corresponding to an averaging time period of $2^{-J} \times 86400 \mathrm{~s}$ ) are referred to as smooths denoted by $S_{J}$. Further, the differences between two subsequent smooths are called the details, $D_{J}\left(=S_{J+1}-S_{J}\right)$, and contain the variability (or fluctuation behavior) within a frequency band delimited by two harmonics. The averaging time periods and wavenumber ranges $\left(\mathrm{km}^{-1}\right)$ corresponding to each wavelet detail $D_{J}$ from $J=3$ to $J=13$ are given in Table 2 . Transformation from time or frequency domain to wavenumber space is accomplished using the frozen turbulence hypothesis (Cahalan and Snider, 1989). It states that the variability in the surface radiation is mainly dominated by the advection of the spatial structures of the cloud fields across the point of observation rather than local changes of the fields. Hence, the frequency domain $(f)$ is converted to wavenumber scale $k(=2 \pi / \lambda$, where $\lambda$ is the wavelength in $\mathrm{m}$ or $\mathrm{km}$ ) by assuming a mean advection velocity $v(=\lambda f)$.

Figure 2 shows the results of the MRA applied to the global radiation $(G)$ and to the global transmittance $(T)$ for measurements from the pyranometer station located at FZJ (hereafter, referred as PYR76) on 25 April 2013 for scales $J=3$ to $J=12$ (i.e., $3 \mathrm{~h}$ to $21 \mathrm{~s}$ ). On this day, light fog prevailed in the morning with some cirrus clouds. Thereafter, broken cumulus mediocris clouds were observed until late afternoon, followed by rapidly increasing low stratus clouds leading to an overcast sky by evening. The left panel of Fig. 2 contains 10 smoothed versions $\left(S_{J}, J \in[3,12]\right)$, the smooths of the original time series corresponding to averaging timescales from $3 \mathrm{~h}$ to $21 \mathrm{~s}$. The right panels of Fig. 2 show the corresponding details $\left(D_{J}, J \in[3,11]\right)$. As the scale $J$ decreases, the time series of transmittance details ex- 
Table 2. Averaging time periods and wavenumber range corresponding to each wavelet detail $\left(D_{J}\right)$.

\begin{tabular}{|c|c|c|c|c|c|c|c|c|c|c|c|}
\hline $\begin{array}{l}\text { Wavelet } \\
\text { detail }\end{array}$ & $D_{3}$ & $D_{4}$ & $D_{5}$ & $D_{6}$ & $D_{7}$ & $D_{8}$ & $D_{9}$ & $D_{10}$ & $D_{11}$ & $D_{12}$ & $D_{13}$ \\
\hline $\begin{array}{l}\text { Time } \\
\text { periods }\end{array}$ & $\begin{array}{l}1.5- \\
3.0 \mathrm{~h}\end{array}$ & $\begin{array}{r}45- \\
90 \mathrm{~min}\end{array}$ & $\begin{array}{r}22.5- \\
45 \mathrm{~min}\end{array}$ & $\begin{array}{r}11.25- \\
22.5 \mathrm{~min}\end{array}$ & $\begin{array}{r}5.6- \\
11.25 \mathrm{~min}\end{array}$ & $\begin{array}{r}2.8- \\
5.6 \mathrm{~min}\end{array}$ & $\begin{array}{r}1.4- \\
2.8 \mathrm{~min}\end{array}$ & $\begin{array}{l}42- \\
84 \mathrm{~s}\end{array}$ & $\begin{array}{l}21- \\
42 \mathrm{~s}\end{array}$ & $\begin{array}{r}10.5- \\
21 \mathrm{~s}\end{array}$ & $\begin{array}{l}5.25- \\
10.5 \mathrm{~s}\end{array}$ \\
\hline $\begin{array}{l}\text { Wavenumber } \\
\text { range }\left(\mathrm{km}^{-1}\right)\end{array}$ & $\begin{array}{r}0.12- \\
0.23\end{array}$ & $\begin{array}{r}0.23- \\
0.47\end{array}$ & $\begin{array}{r}0.47- \\
0.93\end{array}$ & $\begin{array}{r}0.93- \\
1.86\end{array}$ & $\begin{array}{r}1.86- \\
3.72\end{array}$ & $\begin{array}{r}3.72- \\
7.45\end{array}$ & $\begin{array}{r}7.45- \\
14.9\end{array}$ & $\begin{array}{r}14.9- \\
29.8\end{array}$ & $\begin{array}{r}29.8- \\
59.6\end{array}$ & $\begin{array}{l}59.6- \\
119.2\end{array}$ & $\begin{array}{r}119.2- \\
238.3\end{array}$ \\
\hline
\end{tabular}
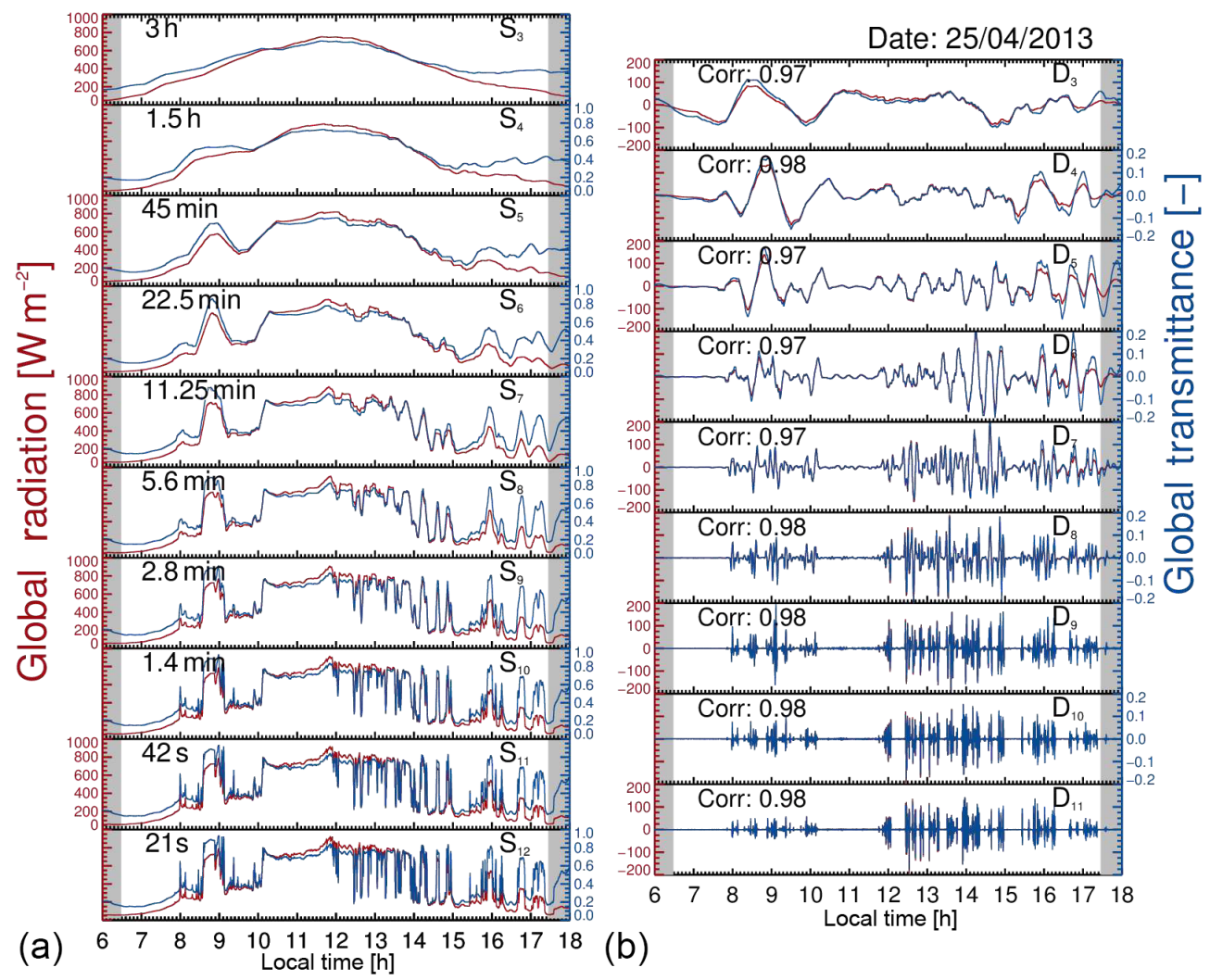

Figure 2. Multiresolution analysis of global radiation (red) and corresponding transmittance (blue) showing smooths (left panel) and details (right panel) as a function of local time (in hours, h) for a pyranometer station at FZJ on 25 April 2013. Shaded gray region on both panels correspond to the region with solar zenith angle $>75^{\circ}$. The smoothing time is given in the left panels, while the correlation of the details in global radiation and transmittance is listed in the right panels.

hibit significant variability. Large fluctuations are observed in details $D_{3}, D_{4}$, and $D_{5}$, which can be related to variability in transmission resulting from longer-term changes in dominant cloud structures and composition ( $S_{12}$ in Fig. 2). A higher number details do not show this as they examine local-scale variability in cloud features ( $D_{9}$ to $\left.D_{11}\right)$. Note that the MRA results were limited to solar zenith angle below $75^{\circ}$ to exclude edge effects. Based on Percival (1995), the maximum overlap discrete wavelet transform decomposes the variance of a time series on a scale-by-scale basis and can be estimated from the variance (var) of the MODWT coefficients as given below:

$\operatorname{var}\left(T_{J}\right)=\operatorname{var}\left(S_{J}\right)+\sum_{j=1}^{J} \operatorname{var}\left(D_{j}\right)$

This result can be generalized to the calculation of the correlation, where the wavelet coefficients of two time series can be used to provide an estimate of the correlation at a given scale (Whitcher et al., 2000).

An effective graphical technique to the MRA is the horizon graph (Heer et al., 2009). As illustrative examples, the horizon graphs of the global transmittance details for different scales (see Table 2) from the PYR76 station are shown 
(a) Clear - 4 May 2013

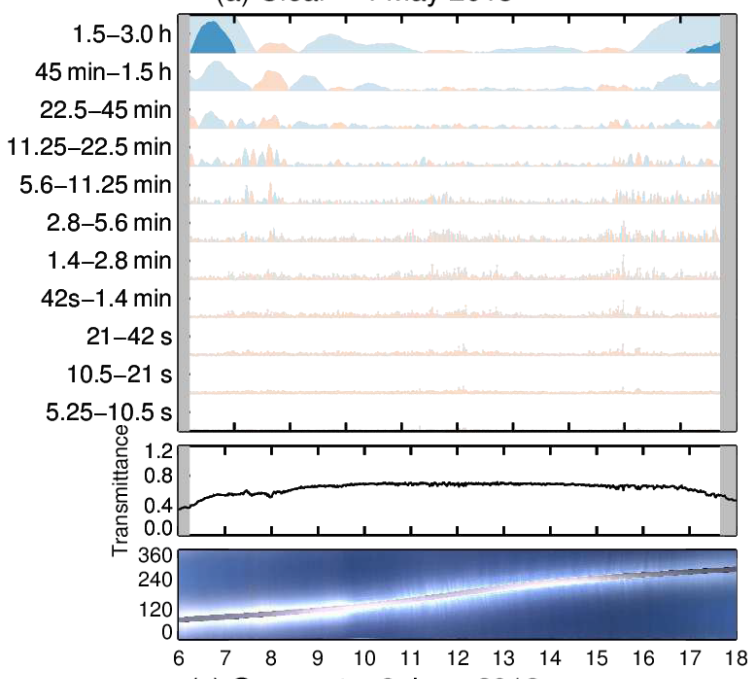

(c) Overcast - 9 June 2013

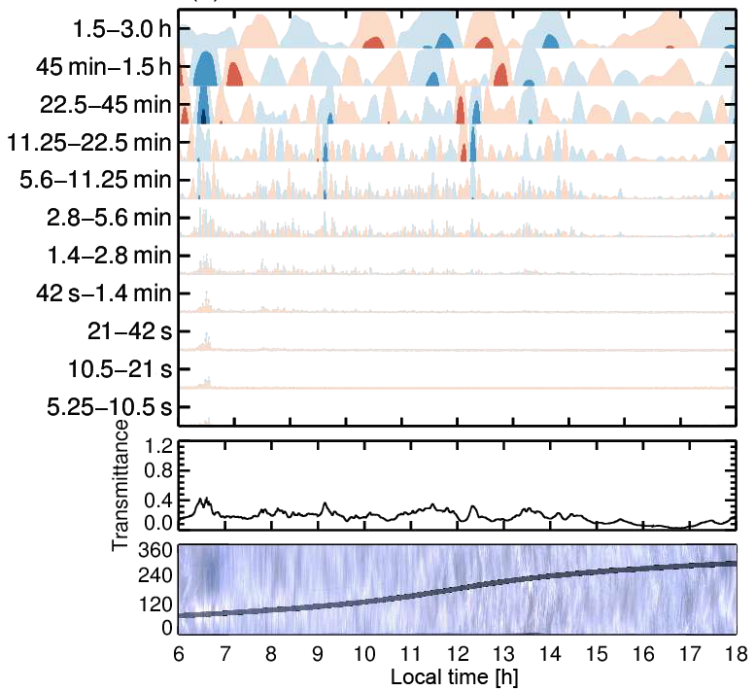

(b) Cirrus - 16 July 2013

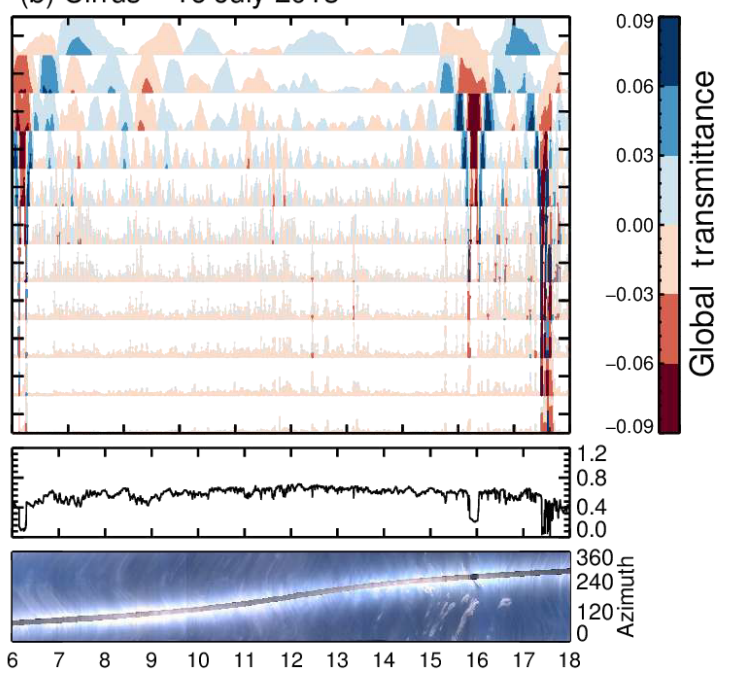

(d) Broken clouds - 25 April 2013

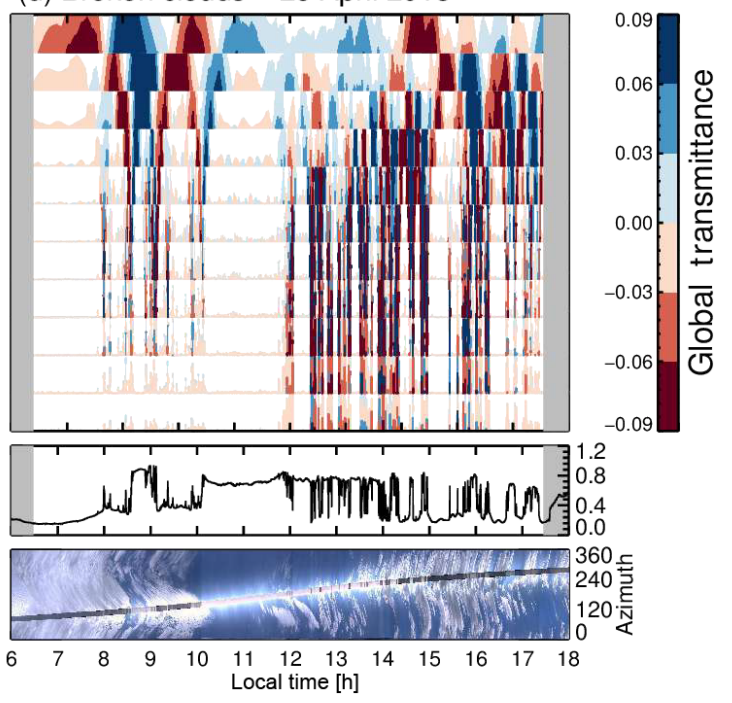

Figure 3. Horizon graphs for MRA of global transmittance from a pyranometer station at FZJ during the HOPE campaign represented as a function of local time (in h) for different sky conditions: (a) clear - 4 May 2013, (b) cirrus - 16 July 2013, (c) overcast - 9 June 2013, and (d) broken clouds - 25 April 2013. The top panels represent the horizon plots of transmittance details. Middle panels represent the original time series of transmittance. The $t$-azi plots of the sky imager at $45^{\circ}$ elevation angle are shown in the bottom panels. Shaded gray color in the top and middle panels of (a) and (d) corresponds to the region with solar zenith angles $>75^{\circ}$. A horizon graph is constructed by dividing a normal line plot into bands defined by uniform value ranges. The bands are then layered to reduce the chart height. Negative values (red bands) can be mirrored or offset onto the same space as positive values (blue bands) such that the colors are differentiated. These layered bands are nested together. Such a visualization allows us to identify extraordinary behaviors or predominant patterns, view changes, interpret each of the time series independently from the others, and perform comparisons between the different temporal periods (Few, 2008).

in Fig. 3 for days with different sky conditions: clear (4 May 2013), cirrus (16 July 2013), overcast (9 June 2013), and broken clouds (25 April 2013). Each row in the top panel of Fig. 3 includes a different detail of the MRA, while the middle panel shows the original time series of global transmittance. In addition, the $t$-azi plots at $45^{\circ}$ solar elevation angle are included as lower panels to illustrate the sky conditions during each observation day. While the fluctuations in the transmittance at different lower frequencies can be perceived from the contrasting color bands, significant variability can be observed in the situations with broken clouds even at high frequencies corresponding to periods of $1 \mathrm{~min}$ or shorter.

\subsection{Spatial representativeness of point measurements}

From the MRA, the wavelet power spectrum of transmittance can be calculated (Sec. 3.1), which describes the partitioning of signal power into frequency ranges, and reflects the characteristics of the prevailing sky conditions. Addition- 
ally, the spatial autocorrelation function describes the similarity of variations in the time series measured at two stations as a function of their distance. By determining both the power spectrum and the frequency-dependent spatial autocorrelation function across the observation domain under different sky conditions, the representativeness of a point measurement for an area-averaged value can be quantified, including the expected deviation. Various statistical parameters, namely the variance, covariance, and explained variance linking the time series of a point measurement to that of an area-averaged value, are derived in Appendix A. In this study, we consider three typical spatial areas $(A)$ of interest with $1 \mathrm{~km} \times 1 \mathrm{~km}, 3.2 \mathrm{~km} \times 3.2 \mathrm{~km}$ and $10 \mathrm{~km} \times 10 \mathrm{~km}$. The expected deviation $(\delta)$ between a point measurement and an area-averaged value for a surrounding domain is calculated as

$\delta_{J}=\sqrt{\left(1-\gamma_{S, J}^{2}\right) \cdot \operatorname{var}\left(S_{J}\right)+\sum_{j=1}^{J}\left(1-\gamma_{D, j}^{2}\right) \cdot \alpha_{A, j} \cdot \operatorname{var}\left(D_{j}\right)}$,

where the variance of the transmittance smooths $\left(S_{J}\right)$ and details $\left(D_{j}\right)$ are obtained from the power spectrum of the point measurement, and $\alpha_{A}$ (from Eq. A11) is a linear reduction factor relating the variance of the point measurement (from Eq. A2) to the variance of an area-averaged time series (from Eq. A8). The explained variance (i.e., $\gamma_{S, J}^{2}$ and $\gamma_{D, J}^{2}$ from Eq. A10) between the point and area-averaged values are obtained separately for transmittance smooths $\left(S_{J}\right)$ and details $\left(D_{J}\right)$ for the different spatial and temporal scales. Then, the expected deviation $\delta_{J}$ for each wavelet detail is calculated based on the explained variance and summed to yield an estimate of the total variance, accounting for a reduced temporal variability of the spatially averaged transmittance by the reduction factor.

Further, the estimated representativeness error of the transmittance $(\delta T)$ time series can be converted into a deviation in global radiation $(\delta G)$ by multiplication with a fixed value of the top-of-atmosphere solar irradiance, which avoids the known influence of changes in solar zenith angle. A fixed value of $680.4 \mathrm{~W} \mathrm{~m}^{-2}$ is used here, which is half the solar constant and is taken as an estimate of the daytime mean value during summer months for the considered region. This procedure can be adopted to improve photovoltaic power forecasting models under different sky conditions, especially with broken clouds, which require absolute values of radiation instead of transmittance.

\section{Results and discussion}

\subsection{Power spectra of global radiation}

Wavelet-based spectral power density characterize the variability contained in specific frequency intervals for both stationary and non-stationary processes. As the time series of global transmittance results from a non-stationary process (i.e., its statistical properties are not time invariant), the wavelet power spectrum is a suitable tool for the analysis of the variability contained within specific frequency intervals, and to study the effect of temporal and spatial averaging on the variability of the time series.

In Fig. 4, the wavelet power spectrum of the global transmittance is shown together with the cumulative variance (or standard deviation, from Eq. 1) for different sky conditions. The average power spectrum is obtained by averaging the power spectra of all the pyranometer stations. The cumulative variance quantifies the fraction of variance resolved by an observation, which has been smoothed with a specific averaging period, and is determined using the spectral power density decomposition given in Eq. (1). It thus gives an indication for how much variability is lost if averaging is applied to the time series. As the frequency increases, the variability in global transmittance decreases, irrespective of the prevailing sky conditions. However, there are clear differences in the shapes of the power spectra for the different sky conditions. During situations with broken clouds, the variability of transmittance is distinctly higher than for all other cases, irrespective of the considered frequency interval. It is wellknown that in the presence of broken clouds, multiple reflections and scattering events off the sides of clouds and at the surface lead to significant horizontal photon transport and strong 3-D radiative effects. For the associated types of lowlevel clouds, such as fair weather cumulus or towering cumulus, a high global transmittance can frequently be observed at the surface exceeding that of a clear sky, which is usually referred to as "enhancement effect" (Schade et al., 2007). Similar effects also occur when patches of cirrus or altocumulus clouds are present in the field of view, but do not obscure the sun. Boers et al. (2000) also demonstrated that the global radiation is very sensitive to cloud inhomogeneities, in particular for broken-cloud fields due to contributions from the direct radiation. Overall, for broken-cloud fields, strong spatial and temporal variations are present over a wide range of frequencies.

On days with cirrus clouds, the spectral power density is lower than for broken clouds and higher than for clear skies. Due to the changes in solar elevation and thus air mass over the day, a pronounced diurnal cycle in global transmittance is observed in clear-sky situations, which introduces significant variance at longer time periods.

In the case of overcast sky, the variance of transmittance is found to be the lowest at high frequencies (i.e., 10.5-5.25 s), with a steep increase up to a time period of $11.25-22.5 \mathrm{~min}$. Thereafter, the variability is slightly higher and comparable to that observed for cirrus cloud situations. Under a homogeneous overcast sky with optically thick clouds, the global radiation is contained completely in the diffuse component, and the radiance at the cloud base observed from the ground will be relatively uniform over time. However, under partly overcast skies, the global transmittance of clouds is also in- 

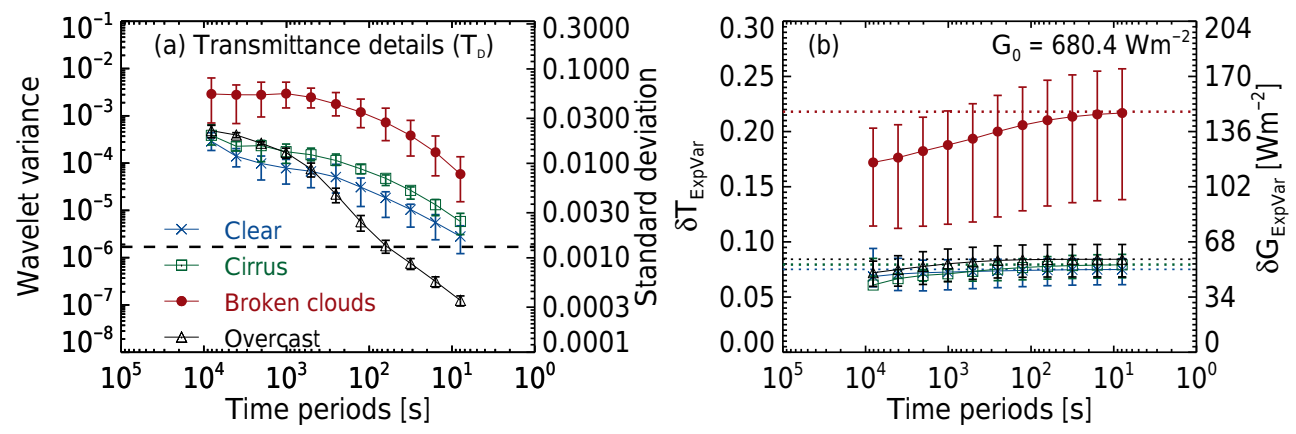

Figure 4. (a) Wavelet variance, and the (b) cumulative variance (from Eq. 1) of global transmittance from all the pyranometer stations in the observation domain as a function of considered frequency/averaging period for cases during the HOPE campaign. As the time period is inversely proportional to the frequency, the time periods (on $x$ axis) are represented in ascending order of frequency scales. The vertical bars around the mean value represent the observed minimum and maximum variances. The dashed horizontal line in (a) corresponds to the measurement uncertainty of our pyranometer. The dashed horizontal lines in (b) denote the total variance of the original time series averaged across all stations within the observation domain.

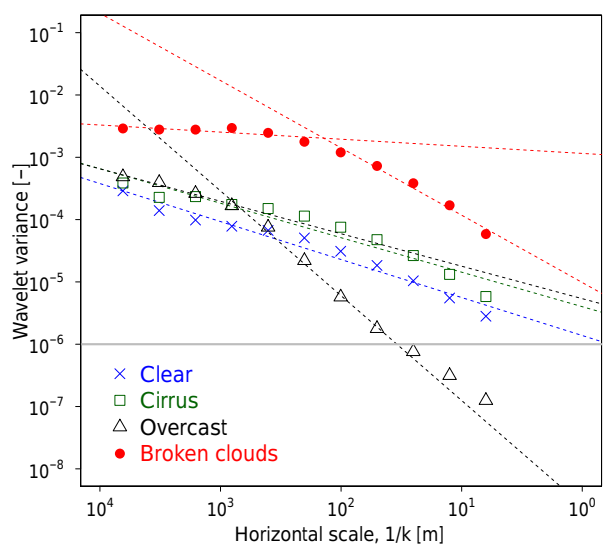

Figure 5. Wavelet variance of global transmittance (as shown in Fig. 4a) represented as a function of horizontal scales denoted by $1 / k$ (in $\mathrm{m}$ ) for different sky conditions during the HOPE campaign. Dashed lines represent the least-square fits at different scale regimes using Eq. (3). The gray color horizontal line correspond to the measurement uncertainty of our pyranometer.

fluenced by multiple reflections of solar radiation between the surface and the cloud base, which causes an increased variance. Note that variations of the transmittance lower than the measurement uncertainty $( \pm 0.0013)$ of our pyranometer stations are neglected here, which is the case for higher frequencies corresponding to time periods below $42 \mathrm{~s}$.

Considering the cumulative explained variance, it can be seen that for broken clouds, high-frequency variability contributes most strongly to the total variance of the global transmittance (Fig. 4b). For other sky conditions (overcast, cirrus and clear), only a small decrease in variability $\left(\sim 10 \mathrm{~W} \mathrm{~m}^{-2}\right)$ is observed, if the averaging period is increased from $1 \mathrm{~min}$ up to $3 \mathrm{~h}$. In case of broken clouds, the corresponding decrease is about 3 times $\left(\sim 34 \mathrm{~W} \mathrm{~m}^{-2}\right)$ the value observed for other sky conditions.
Various studies have described the properties of stratocumulus/cumulus clouds using power spectra (or spectral density, $E$ ) of cloud top height fluctuations, liquid water content (LWC), liquid water path (LWP), or solar radiation transmission as a function of the horizontal spectral scale $(1 / k)$ with a power-law relationship of the form (Boers et al., 1988; Cahalan and Snider, 1989; Davis et al., 1999; Gerber et al., 2001):

$E(k) \approx k^{-\beta}$,

where $k$ is the wavenumber and $\beta$ is the power-law exponent. The power spectrum of global transmittance details as a function of horizontal scale (in m) is shown in Fig. 5 (same as Fig. 4a but with a change of $x$ axis). Here, we examine a least-square fit for single point measurements within the larger context of power spectrum in Eq. (3) for the scale covering $5 \mathrm{~m}$ to $10 \mathrm{~km}$. The dashed lines correspond to leastsquare fits for different scaling regimes under the prevailing sky conditions. For clear and cirrus cloudy skies, the powerlaw exponent is obtained as 0.61 and 0.55 , respectively, for the horizontal scales covering $5 \mathrm{~m}$ to $10 \mathrm{~km}$. This indicates that clear and cirrus cloudy skies resemble a flat and nearly wavenumber-independent spectrum. In case of overcast sky, two distinct regimes with scaling exponents of 0.52 (1.5$10 \mathrm{~km})$ and $1.68(\sim 5 / 3 ; 50 \mathrm{~m}-1.5 \mathrm{~km})$ are observed. The occurrence of a scale break suggests that different physical processes dominate in the two regimes. While the scaling regime above $1.5 \mathrm{~km}$ is much flatter, the lower scaling regime $(<1.5 \mathrm{~km}$ is indicative of the fluctuations in global transmittance as a result of advection. For the cases with broken clouds, two distinctly linear regimes are identified separated by a wavelength of $200 \mathrm{~m}$. The first regime has a flat scaling exponent of $0.11(0.2-10 \mathrm{~km})$, where as the smaller scaling regime has an exponent of $1.1(5-100 \mathrm{~m})$, which indicates a linearly dependent stationary power spectrum. Davis et al. (1999) also reported a "scale-break" at scales of 2-5 $\mathrm{m}$ in the spectral density of LWC indicating a transition of the scal- 
Table 3. Summary of the spectral power density of scalar variables with observed scale regimes and spectral exponents $(\beta)$ as obtained by using Eq. (3) in different studies.

\begin{tabular}{llrll}
\hline Literature reference & Scalar variable & $\begin{array}{r}\text { Spectral } \\
\text { exponent }(\beta)\end{array}$ & Scale regime $(1 / k)$ & Remarks \\
\hline King (1981) & LWC & 1.8 & $2-40 \mathrm{~m}$ & Cumulus \\
\hline Boers et al. (1988) & Cloud top height & 1 & $>900 \mathrm{~m}$ & \\
& & $5 / 3$ & $<900 \mathrm{~m}$ & \\
\hline Cahalan and Snider (1989) & LWP & $5 / 3$ & $0.6-432 \mathrm{~km}$ & \\
& Landsat Band 2 & 3 & $<0.5 \mathrm{~km}$ & Cumulus \\
& reflectivity & 0.6 & $0.5-10 \mathrm{~km}$ & Cumulus \\
& & 3.6 & $100-200 \mathrm{~m}$ & Stratocumulus \\
& & $5 / 3$ & $>200 \mathrm{~m}$ & Stratocumulus \\
\hline Davis et al. (1999) & LWC & $0.9 \pm 0.1$ & $8-12 \mathrm{~cm} \leq 1 / k \leq 2-5 \mathrm{~m}$ & Stratocumulus \\
& & $1.6 \pm 0.1$ & $5 \mathrm{~m} \leq 1 / k \leq 2 \mathrm{~km}$ & \\
\hline Gerber et al. (2001) & LWC & $5 / 3$ & $>5 \mathrm{~m}$ & Stratocumulus \\
& & $5 / 3$ & $>2 \mathrm{~m}$ & Cumulus \\
\hline Present study & Global transmittance & $1.68(\approx 5 / 3)$ & $50 \mathrm{~m}-1.5 \mathrm{~km}$ & Overcast \\
(No cloud typing) & & 0.52 & $1.5-10 \mathrm{~km}$ & Overcast \\
& & 1.1 & $5-100 \mathrm{~m}$ & Broken clouds \\
& & 0.11 & $0.2-10 \mathrm{~km}$ & Broken clouds \\
\hline
\end{tabular}

ing regime from $\beta=\frac{5}{3}(5 \mathrm{~m} \leq 1 / k \leq 2 \mathrm{~km})$ to the one that showed larger variance than expected at smaller scales corresponding to $\beta \leq 1(8-12 \mathrm{~cm} \leq 1 / k \leq 2-5 \mathrm{~m})$ for the stratocumulus/cumulus clouds. At smaller scales, entrainment of environmental air into the clouds changes the cloud microphysics resulting in an enhancement of LWC variance. An overview of various scalar fields with their associated scale regimes and spectral exponents obtained in different studies is given in Table 3.

In Fig. 5, the wavelet variance for all cloud conditions is largest at long time periods implying that large-scale cloud structures with their associated global transmission are important at this scale. The size distribution of broken cumulus/stratocumulus clouds has been studied by Núñez et al (2016); Koren et al. (2008); Cahalan and Snider (1989), which describes the typical distribution of cloud sizes in terms of their number density $N\left(=A^{-C_{1}}\right.$, where $A$ is the cloud area and $C_{1}$ is an exponent determined by a leastsquare fit). These studies also point to the importance of low wavenumbers or large cloud sizes in dominating the variance of the time series of liquid water and solar radiation transmission, with partly cloudy skies characterized by few large clouds and many smaller ones.

It should be noted that the global irradiance is a hemispherically integrated property and thus there cannot be an exact one-to-one relation to the cloud variability or to (directional) radiance variability. However, the irradiance variability should show a correlation to a smoothed cloud structure. Finding an appropriate smoothing kernel requires intensive investigations of the interaction of clouds and radiation in- cluding 3-D radiative effects, and is beyond the scope of this study.

\subsection{Spatial autocorrelation}

An important aspect for assessing the density of a measurement network is the representativeness of observations at one station for other close by network stations as a function of their distance. To investigate this aspect for the network operated during the HOPE campaign, the spatial autocorrelation $\rho$ has been determined as a function of station distance for the wavelet smooth $S_{3}$ and the wavelet details $D_{3}$ to $D_{9}$ of global transmittance, and are shown in Fig. 6. In this plot, points represent the correlation coefficient obtained for the individual station pairs. Results are again shown separately for different sky conditions. The autocorrelation is generally found to decrease as station distance and frequency increases, with significant differences notable depending on sky conditions.

The behavior of the spatial autocorrelation $(\rho)$ as a function of distance between stations ( $d$ in $\mathrm{km}$ ) is shown as a blue line in Fig. 6, and has been modeled by an exponential decay function as given below:

$\rho(d)=\exp \left[-\left(\frac{d}{a}\right)^{b}\right]$,

where $a$ (in $\mathrm{km}$ ) and $b$ (dimensionless exponent) represent fit coefficients. If the station distance is negligible $(d \rightarrow 0)$, then $\rho \rightarrow 1$ (perfect correlation). Similarly, if the station distance is infinite (i.e., $d \rightarrow \infty$ ), then $\rho \rightarrow 0$ (no correlation). We 


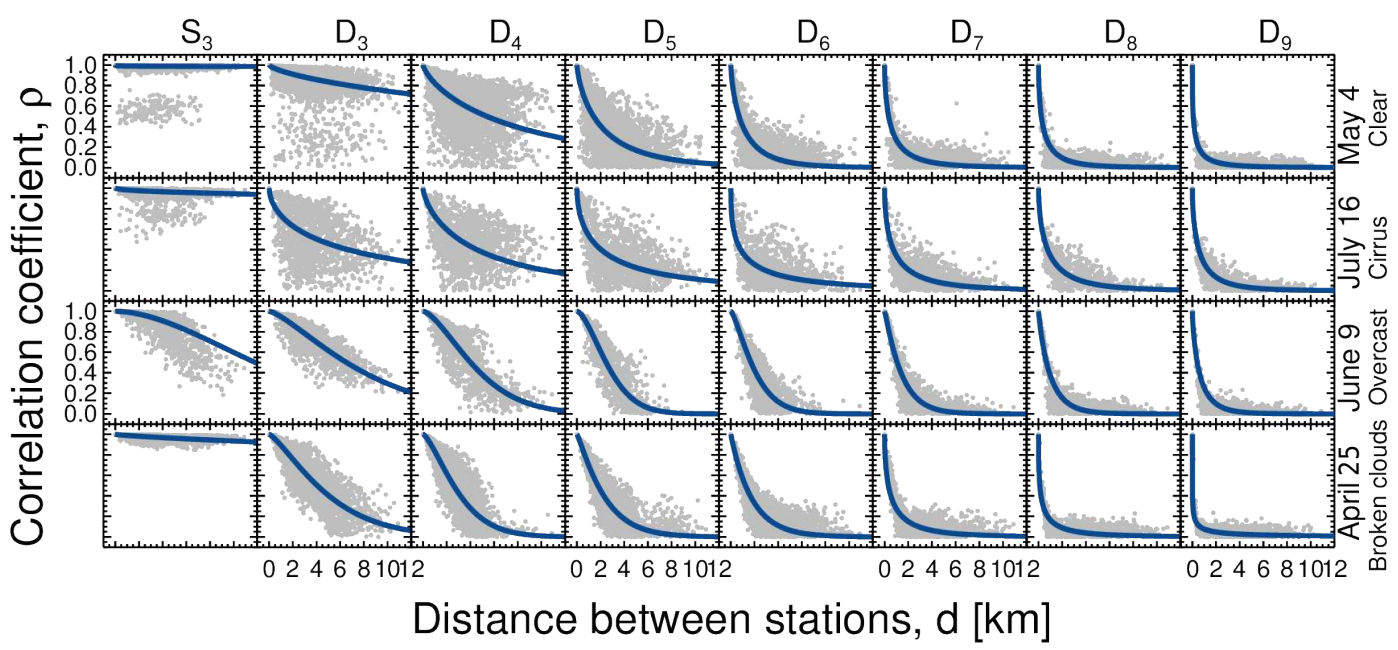

Figure 6. Spatial autocorrelation $\rho$ as a function of station distance $d$ for days with different sky conditions: (a) clear - 4 May 2013 (top row), (b) cirrus - 16 July 2013 (second row), (c) overcast - 9 June 2013 (third row), and (d) broken clouds - 25 April 2013 (last row). Here, $S_{3}$ corresponds to the wavelet smooth of global transmittance at $3 \mathrm{~h}$ averaging timescale, while $D_{3}$ to $D_{9}$ represent the wavelet details of global transmittance.

Table 4. Summary of various parameterizations used for modeling the behavior of spatial autocorrelation $\rho$ as a function of the station distance $d$.

\begin{tabular}{llll}
\hline Literature reference & Averaging periods & Parameterization & Remarks \\
\hline $\begin{array}{l}\text { Long and Ackerman (1995) } \\
\text { Deneke et al. (2009) }\end{array}$ & $\begin{array}{l}1,15,30,60 \mathrm{~min} \text {, and daily } \\
10,20,40 \text { and } 80 \mathrm{~min}\end{array}$ & $\rho=a-b \cdot d^{c}$ & $a, b$ and $c$ are fit coefficients \\
\hline Hoff and Perez (2012) & $1,2,3$ and $4 \mathrm{~h}$ & $\rho=\left(1+\frac{d}{\Delta t \cdot \Delta v}\right)^{-1}$ & $\Delta t$ is the time interval, and \\
Lohmann et al. (2016) & $15 \mathrm{~min}$ & $\Delta v$ is the relative cloud speed \\
\hline Perpiñán et al. (2013) & $10 \times 2^{J} \mathrm{~s}, J \in[0,9]$ & $\rho=a+b \cdot \exp \left(-\frac{d}{c}\right)$ & $a, b$ and $c$ are fit coefficients \\
\hline Slobodda et al. (2015) & $15 \mathrm{~min}$ & $\rho=1-\frac{d^{b}}{a}$ & $a$ and $b$ are fit coefficients \\
\hline Present study & $2^{-J} \times 86400 \mathrm{~s}, J \in[3,14]$ & $\rho=\exp \left[-\left(\frac{d}{a}\right)^{b}\right]$ & $a$ and $b$ are fit coefficients \\
\hline
\end{tabular}

have applied the Levenberg-Marquardt least-squares fitting technique to determine the fit coefficients. When the correlation drops below the $e$-folding value (i.e., $\rho \leq \frac{1}{e}$ ), the associated distance between stations is defined as the decorrelation length. This occurs when the fit coefficient $a$ equals to the station distance $d$ and thus $a$ is referred as the decorrelation length. Figure 7 confirms our expectation that the decorrelation length decreases for increasing frequencies, following an approximately linear trend with slightly different slopes and offsets depending on sky conditions. The RMSE, which measures the quality of fit has been found to decrease linearly with decreasing frequency.

An overview of various parameterizations used for modeling the behavior of the spatial autocorrelation function as a function of station distance is presented in Table 4. Long and Ackerman (1995) used a linear model to parameterize the dependence of correlation of the time series of global radiation measurements at different sites based on their distance of separation $(\lesssim 100 \mathrm{~km})$. Subsequently, the same linear function was used to fit the correlation of wavelet smooths corresponding to the transmittance (from Multi-Filter Rotating Shadowband Radiometer) and reflectance (from Meteosat SEVIRI pixels) as a function of distance in the study by Deneke et al. (2009). They observed that the correlation falls off faster than linear at small distances due to the exponent $(c<1)$. In a study on the correlation between the solar power generation of solar cell inverters, it was shown that the correlation was dependent on the distance between the inverters, the wavelet timescales, and the amplitude of daily fluctuations (Perpiñán et al., 2013). They used an exponential decay model with some constraints on the fit coefficients. The spatial decorrelation of the time series of SEVIRI pixels for its 


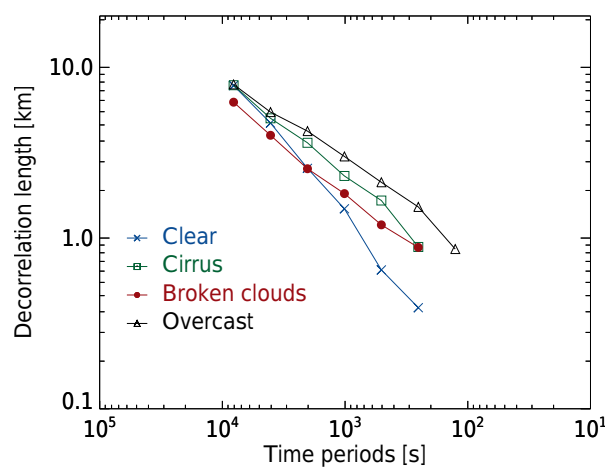

Figure 7. Decorrelation lengths $a$ (in $\mathrm{km}$ ), determined as $e$-folding time of the spatial correlation function, and its dependence on the time period of variations.

solar and infrared channels was studied for different cloud amounts as a function of distance $(\lesssim 200 \mathrm{~km})$ at different locations over Europe (Slobodda et al., 2015). In the most recent study, Lohmann et al. (2016) used the Hoff and Perez (2012) model of spatial correlation using a range of cloud speeds from 2 to $10 \mathrm{~m} \mathrm{~s}^{-1}$, and demonstrated that the Hoff and Perez (2012) model is not able to capture the correlation structure for mixed sky conditions.

In our study, the spatial correlation of transmittance variations decays faster than linear at small distances as is indicated by the exponent $(b)$ in Eq. (4), and depends strongly on the type and/or amount of clouds. Small-scale cloud features significantly decrease the correlation on days with broken clouds. The side reflections from clouds is strongly enhanced in broken-cloud conditions and could be important for lowering the correlation (Núñez et al, 2016). We point out a likely influence of the cloud speed on the decorrelation length. Additionally, anisotropy in the decorrelation relative to the direction of cloud motion is expected, and might influence the observed relationship (Hinkelman, 2013). In the following parts of the paper, the empirically fitted autocorrelation functions are used to represent the spatial variability at a given temporal frequency across the observation domain.

\subsection{Spatial representativeness of a point measurement}

The spatial representativeness of a point measurement at the center of a domain of interest depends on the size of the domain, the temporal averaging applied, and the spatiotemporal variability present in the observations. Generally, higher variability leads to a reduction of representativeness. Statistically optimum methods for spatial averaging have been developed to provide spatial means including uncertainty estimates when using data from a number of stations (Kagan, 1979; Gandin, 1993), and allow us to provide an estimate of the representativeness error, defined here as deviation of point measurement from the spatial mean for a considered domain. These techniques have been previously applied to
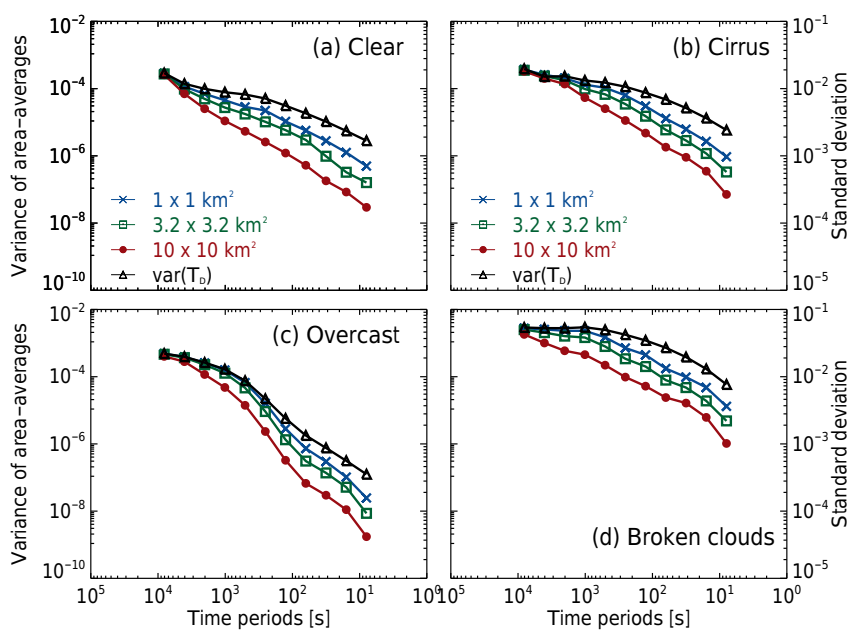

Figure 8. Power spectrum of spatially averaged transmittance as a function of frequency under different sky conditions: (a) clear, (b) cirrus, (c) overcast, and (d) broken clouds; $\operatorname{var}\left(T_{D}\right)$ denotes the power spectrum of a point measurement of global transmittance as shown in Fig. 4a.

global surface air temperature and precipitation measurements, as well as surface networks of soil moisture observations (Vinnikov et al., 1990, 1999). Similarly, the observations from our high-density pyranometer network can be used to evaluate or quantify the uncertainties due to smallscale cloud inhomogeneity during validation studies. In this paper, we utilize the spatial autocorrelation functions determined in the previous section to calculate the power spectral density of spatial averages, and the deviation of spatial averages from point measurements. Thereby, we avoid averaging of multiple stations to obtain an approximation of a spatial average, but rely on the assumption that the global transmittance field within the observation domain is statistically homogeneous and isotropic, and that its autocorrelation function follows Eq. (4). A concise mathematical treatment for quantifying the effects of spatial and temporal averaging is given in Appendix A.

In Fig. 8, the power spectra of area-averaged transmittances for different domain sizes are compared to those of a point measurement. They generally follow a similar trend compared to the point measurement irrespective of sky conditions, but show a stronger decrease of variability with increasing frequency and area, which illustrates that spatial averaging acts as low-pass filter. At lower frequencies corresponding to time periods of $1.5-3 \mathrm{~h}$, only minor differences in variability are notable for time series for spatially extended domains and point observations, at least for the range of domain sizes considered here. However, at higher frequencies, the variability of the spatially averaged global transmittance is significantly reduced compared to that of the point observation, irrespective of the prevailing sky condition. Again, the variance of spatially averaged transmittance is observed 

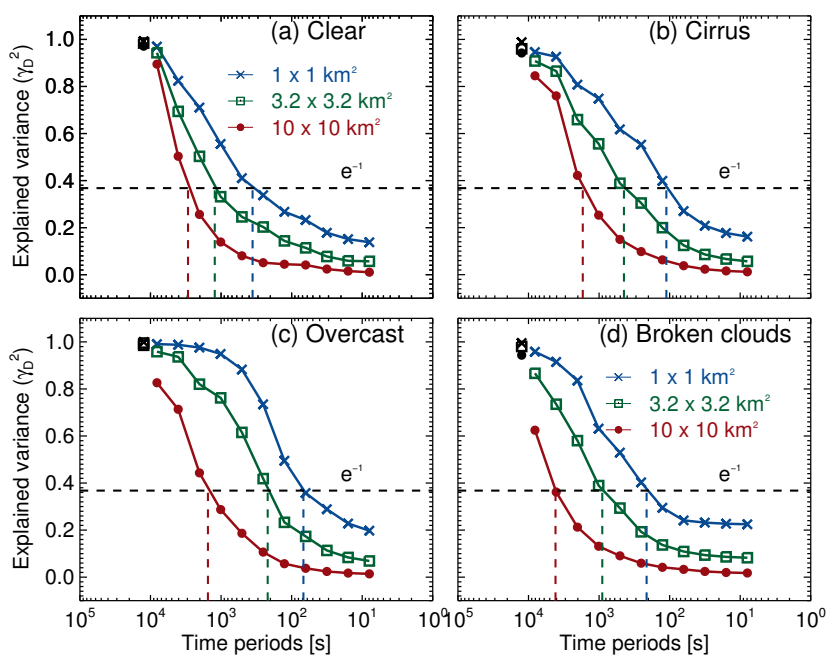

Figure 9. Explained variance $\left(\gamma_{D}^{2}\right.$, the square of the crosscorrelation) between the wavelet details of the point measurement and the area-averaged values of global transmittance as a function of their time period and for different domain sizes and sky conditions: (a) clear, (b) cirrus, (c) overcast, and (d) broken clouds. The black symbols respectively denote the explained variance $\left(\gamma_{S_{3}}^{2}\right)$ of wavelet smooths $S_{3}(3 \mathrm{~h})$ corresponding to the domain size. The black dashed horizontal line in each of the sub-figures represent the $e$-folding time of $e^{-1}=0.368$ and the dashed vertical lines corresponds to the decorrelation period for the selected domain sizes.

to be higher under broken clouds at all frequencies and spatial resolutions, compared to that for clear, cirrus, and overcast conditions.

At $10 \mathrm{~km} \times 10 \mathrm{~km}$ and for variations corresponding to time periods of $1.5-3 \mathrm{~h}$, the spatially averaged variance is lower by 10 (clear), 16 (cirrus), 18 (overcast), and $38 \%$ (broken clouds) than the variability observed by a single station. Even for a domain size of $1 \mathrm{~km} \times 1 \mathrm{~km}$, the spatially averaged variance is $2-4 \%$ lower than the variability obtained by a point measurement for the considered sky conditions.

The level of similarity between two time series is often expressed by metrics such as the explained variance or the RMSE, and suitable averaging timescales are often determined by studying the sensitivity of these metrics to the choice of averaging scale. The explained variance $\left(\gamma_{D}^{2}\right)$, given by the square of the cross-correlation between the time series at a single station and its area-averaged counterpart, is used here and shown in Fig. 9 for different sky conditions, including its dependence on the temporal scales of averaging for the three domain sizes. The explained variance is thus used here as a measure to quantify the synchronicity of variations, while the power spectrum quantifies their mean amplitude. An exponential decay of the explained variance is observed as the temporal frequency increases for all spatial domain sizes. As expected, the deviation between a single station and an area average becomes larger at higher frequencies and for larger spatial areas. Consequently, the variations ob-
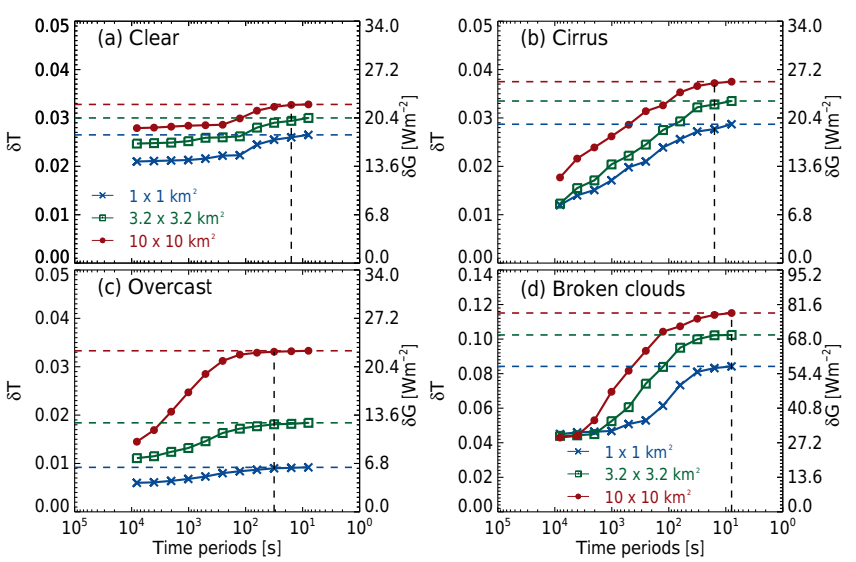

Figure 10. Area-averaging error in the global transmittance $(\delta T)$ and corresponding global radiation $\left(\delta G\right.$, in $\left.\mathrm{W} \mathrm{m}^{-2}\right)$ with different sky conditions: (a) clear, (b) cirrus, (c) overcast, and (d) broken clouds for different domain sizes represented as a function of averaging time periods. The dashed horizontal lines correspond to the maximum deviation observed for the different domain sizes. Dashed vertical lines represent the minimum-averaging time above which the area-averaging errors are less sensitive at different spatial resolutions.

served at a single station should no longer be used to predict the variations of the area-averaged transmittance at higher frequencies and for larger domains. Further, the explained variance between the wavelet smooth $S_{3}(3 \mathrm{~h})$ of the point measurement and the area-averaged values of global transmittance is insensitive to the domain sizes. The decorrelation times for which the point and area-averaged variations become essentially uncorrelated is defined here by the $e$-folding value of $e^{-1}(=0.368)$ for the correlation, and are listed in Table 5 for the different sky conditions. The $e$-folding time of $6 \mathrm{~min}$ indicates that variations with frequencies higher than $1 / 6 \mathrm{~min}^{-1}$ are more or less uncorrelated between the point measurement and a spatial area of $1 \mathrm{~km} \times 1 \mathrm{~km}$. It should also be noted that the spatial average has a significantly lower power spectral density at these frequencies. We thus think these variations associated with small-scale fluctuations in clear-sky turbidity and only evident in the point measurements are possibly induced by small-scale structure in water vapor and/or aerosols. However, we cannot rule out that such variability corresponds to undetected small clouds or even measurement artifacts such as shading of the instruments by birds.

Finally, the deviation between point observations and spatial averages is determined for different domain sizes and temporal-averaging periods, combining the two effects discussed before. The magnitude of the expected deviation as a function of domain size and temporal-averaging period is shown in Fig. 10 for different sky conditions. It is generally observed that the representativeness error increases with the size of the spatial domain, and decreases for longer averag- 
Table 5. The $e$-folding times ( $\mathrm{min}$ ) for the explained variance between the point measurement and area-averaged values under different sky conditions.

\begin{tabular}{lrrr}
\hline Sky condition & $A=1 \times 1 \mathrm{~km}^{2}$ & $A=3.2 \times 3.2 \mathrm{~km}^{2}$ & $A=10 \times 10 \mathrm{~km}^{2}$ \\
\hline Clear & $6 \mathrm{~min}$ & $21 \mathrm{~min}$ & $49 \mathrm{~min}$ \\
Cirrus & $2 \mathrm{~min}$ & $7 \mathrm{~min}$ & $28 \mathrm{~min}$ \\
Overcast & $1 \mathrm{~min}$ & $4 \mathrm{~min}$ & $26 \mathrm{~min}$ \\
Broken clouds & $4 \mathrm{~min}$ & $15 \mathrm{~min}$ & $70 \mathrm{~min}$ \\
\hline
\end{tabular}

Table 6. Mean deviation between point measurement and spatial averages of global transmittance $(\delta T)$ and corresponding global radiation $\left(\delta G\right.$, in $\left.\mathrm{W} \mathrm{m}^{-2}\right)$ for different averaging time periods and domain sizes.

\begin{tabular}{|c|c|c|c|c|c|c|c|}
\hline \multirow[b]{3}{*}{$\begin{array}{l}\text { Sky } \\
\text { condition }\end{array}$} & \multirow[b]{3}{*}{$\begin{array}{r}\text { Domain } \\
\text { size }\left(\mathrm{km}^{2}\right)\end{array}$} & \multicolumn{6}{|c|}{ Averaging time periods } \\
\hline & & \multicolumn{2}{|c|}{$S_{3}(3.0 \mathrm{~h})$} & \multicolumn{2}{|c|}{$D_{6}(11.25-22.5 \mathrm{~min})$} & \multicolumn{2}{|c|}{$D_{13}(5.25-10.5 \mathrm{~s})$} \\
\hline & & $\delta T$ & $\begin{array}{r}\delta G \\
\left(\mathrm{~W} \mathrm{~m}^{-2}\right)\end{array}$ & $\delta T$ & $\begin{array}{r}\delta G \\
\left(\mathrm{~W} \mathrm{~m}^{-2}\right)\end{array}$ & $\delta T$ & $\begin{array}{r}\delta G \\
\left(\mathrm{~W} \mathrm{~m}^{-2}\right)\end{array}$ \\
\hline \multirow[t]{3}{*}{ Clear } & $1 \times 1$ & 0.0019 & 1.3 & 0.0213 & 15.0 & 0.0265 & 18.0 \\
\hline & $3.2 \times 3.2$ & 0.0024 & 1.6 & 0.0252 & 17.0 & 0.0300 & 20.0 \\
\hline & $10 \times 10$ & 0.0027 & 1.8 & 0.0284 & 19.0 & 0.0328 & 22.0 \\
\hline \multirow[t]{3}{*}{ Cirrus } & $1 \times 1$ & 0.0046 & 3.0 & 0.0171 & 12.0 & 0.0287 & 20.0 \\
\hline & $3.2 \times 3.2$ & 0.0082 & 6.0 & 0.0204 & 14.0 & 0.0335 & 23.0 \\
\hline & $10 \times 10$ & 0.0101 & 7.0 & 0.0262 & 18.0 & 0.0375 & 26.0 \\
\hline \multirow[t]{3}{*}{ Overcast } & $1 \times 1$ & 0.0015 & 1.0 & 0.0068 & 5.0 & 0.0092 & 6.0 \\
\hline & $3.2 \times 3.2$ & 0.0033 & 2.0 & 0.0132 & 9.0 & 0.0184 & 13.0 \\
\hline & $10 \times 10$ & 0.0074 & 5.0 & 0.0247 & 17.0 & 0.0333 & 23.0 \\
\hline Broken & $1 \times 1$ & 0.0076 & 5.0 & 0.0468 & 32.0 & 0.0842 & 57.0 \\
\hline \multirow[t]{2}{*}{ clouds } & $3.2 \times 3.2$ & 0.0148 & 10.0 & 0.0525 & 36.0 & 0.1024 & 70.0 \\
\hline & $10 \times 10$ & 0.0178 & 12.0 & 0.0695 & 47.0 & 0.1151 & 79.0 \\
\hline
\end{tabular}

ing periods. Also, the error converges against a limit value at high frequencies, indicating that the contribution of highfrequency variability beyond the frequency range considered here only causes a negligible further increase of the representativeness error.

Table 6 provides a quantitative estimate of the deviations of both global transmittance and corresponding global radiation for three different domain sizes, three averaging periods, and for different sky conditions. As the averaging frequency interval and domain size increases, the deviation between point measurement and corresponding area averages increases, irrespective of the prevailing sky condition. As expected, the range of deviations for both long $\left(3 \mathrm{~h}, S_{3}\right)$ and short $\left(5.25 \mathrm{~s}\right.$, including $\left.D_{13}\right)$ averaging periods is the largest for broken clouds.

On clear days, the representativeness error of a point measurement for an area-averaged mean value increases only slightly as the averaging period decreases, and ranges from 2.1 to $3.3 \%$. The difference between the maximum and minimum deviations resulting from the choice of averaging period is found to be around $0.6 \%\left(\sim 4 \mathrm{~W} \mathrm{~m}^{-2}\right)$ regardless of spatial domain.
The range of deviations of a point observation under cirrus clouds is found to be around $1.6 \%\left(\sim 11 \mathrm{~W} \mathrm{~m}^{-2}\right.$ for a $1 \mathrm{~km} \times 1 \mathrm{~km})$ domain, and $2 \%\left(\sim 14 \mathrm{~W} \mathrm{~m}^{-2}\right.$ for both $3.2 \mathrm{~km} \times 3.2 \mathrm{~km}$ and $10 \mathrm{~km} \times 10 \mathrm{~km}$ ) domains, and for $3 \mathrm{~h}$ temporal averaging. A strongly increasing linear trend of the deviations is found from a reduction of averaging period, indicating that small-scale changes of cirrus cloud properties resulting from microphysical, dynamical, and radiative processes can be removed effectively by sufficiently long temporal averaging. Dobbie and Jonas (2001) investigated the structure and lifetime of cirrus clouds using model simulations, and concluded that radiation together with latent heating leads to much more dynamic and inhomogeneous clouds.

During overcast skies, the representativeness error again increases substantially with increasing domain size, doubling and tripling its magnitude when going from $1 \mathrm{~km} \times 1 \mathrm{~km}$ to domain sizes of $3.2 \mathrm{~km} \times 3.2 \mathrm{~km}$ and $10 \mathrm{~km} \times 10 \mathrm{~km}$ for short averaging periods. While the small deviations for a $1 \mathrm{~km} \times 1 \mathrm{~km}$ domain below $1 \%$ indicate that the hemispheric nature of a pyranometer measurement is able to resolve variability at the kilometer scale well, large-scale variations in 


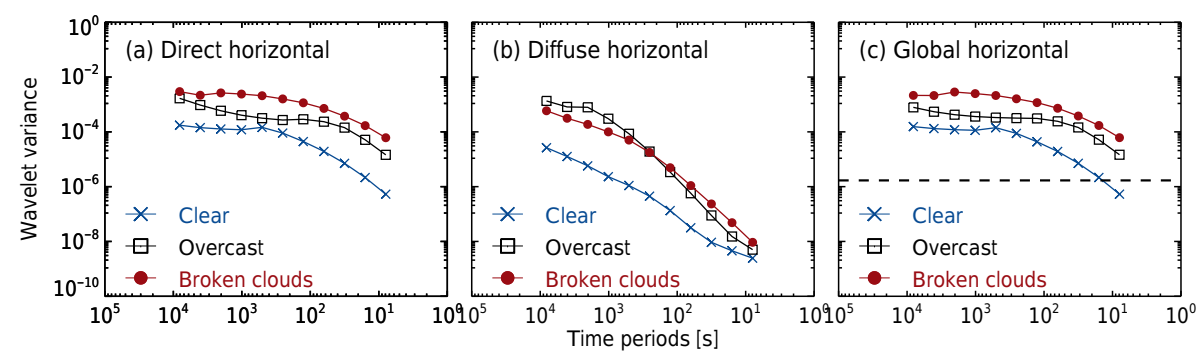

Figure 11. Power spectrum of the (a) direct, (b) diffuse, and (c) global transmittance as a function of temporal frequency for a clear-sky (4 July 2015), overcast (21 June 2015), and a broken cloudy-sky (17 June 2015) conditions observed during the HOPE Melpitz experiment. The black dashed horizontal line in (c) represents the combined measurement uncertainty of the pyranometer system.

cloud optical properties lead to deviations up to $3.3 \%$ in transmittance or $22.6 \mathrm{~W} \mathrm{~m}^{-2}$ for a $10 \mathrm{~km} \times 10 \mathrm{~km}$ domain.

As expected, the magnitude of deviations in global transmittance and corresponding radiation due to the limited representativeness of a point observation is found to be distinctly higher for all considered domain sizes and frequency intervals under broken cloudy situations. It varies from 4.5 to $11.5 \%\left(\sim 31.1-78.3 \mathrm{~W} \mathrm{~m}^{-2}\right)$ over spatial areas ranging from $1 \mathrm{~km} \times 1 \mathrm{~km}$ to $10 \mathrm{~km} \times 10 \mathrm{~km}$. Again, deviations decrease strongly with increasing averaging period by more than $50 \%$ for $3 \mathrm{~h}$ averaging. An interesting observation is that the representativeness error at different spatial resolutions seems to converge for $1 \mathrm{~h}$ or longer averaging periods. Hinkelman et al. (2007) reported that cumulus cloud inhomogeneity gave rise to an instantaneous error in global radiation of up to $40 \mathrm{~W} \mathrm{~m}^{-2}$ or even higher at different solar zenith angles. This well-known "broken-cloud effect" arises from variability in the direct and diffuse radiation (based on solar position), and can lead to an enhancement of global radiation above clearsky conditions. As a result, large inconsistencies can occur for collocated satellite and surface measurements during broken cloudy conditions. Similarly, Barker and Li (1997) reported significant deviations from 1-D radiative transfer due to horizontal photon transport if the horizontal dimensions of a considered atmospheric column are decreased. Horvath and Davies (2004) provided further evidence for the relevance of 3 -D radiative effects through the observed anisotropy in the reflected solar radiation, which increasingly deviates from 1$D$ radiative transfer if the spatial resolution of the satellite is increased. Zinner and Mayer (2006) reported that at $1 \mathrm{~km}$ scale, the errors associated with horizontal photon transfer and the plane-parallel approximation cancel at least to some degree for stratiform boundary layer clouds.

Based on our findings for different sky conditions, the comparison of time series corresponding to spatial averages of global radiation on the one hand, and point measurements on the other hand, can result in large deviations due to the limited representativeness of the point measurement. Similar effects are expected to occur for other observables such as liquid water path. To address this issue of representativeness, we recommend here to apply a low-pass filter, which removes variability at higher frequencies without significant correlation. Even for lower frequencies, a low-pass filter should be applied to adjust the power spectrum of a point time series towards that of the spatially averaged time series, at least if the reduction factor of the amplitude of variations shown in Fig. 4 can be estimated. Nevertheless, significant deviations cannot always be avoided, but should be quantified, for example using the methodology introduced in this paper.

\subsection{Power spectra of direct and diffuse irradiance}

Variability in global radiation results from the combined variability of the direct and diffuse radiation components. During the HOPE Melpitz campaign (May-July 2015; Macke et al., 2016), two EKO ML-020VM pyranometers were operated in close proximity, using a sun tracker and shading to obtain the diffuse radiation from one of the instruments, and to study this aspect in more detail.

Power spectra of the global, direct, and diffuse transmittance are shown in Fig. 11, and allow for an assessment of the individual contributions. It is evident from the plots that the spectra for the direct and global components are very similar for all sky conditions. The spectral power density resulting from variations of the diffuse transmittance is lower, and only contains significant variations at low frequencies, again a conclusion valid for all sky conditions. Please note that the large variability in direct horizontal transmittance also in overcast conditions is due to our classification. In particular, even on the days classified as overcast, some periods with significant direct irradiance due to cloud gaps were observed and evidently dominate the power spectrum of the global transmittance.

This behavior highlights that the strong influence of the direct radiation on the power spectra of global radiation. A plausible explanation is the hemispherical field of view of the diffuse radiation observations, which is less sensitive to small-scale variations in cloud properties than the direct beam of sunlight. Boers et al. (2000) also demonstrated that the global radiation is very sensitive to cloud inhomogeneities, in particular for broken-cloud fields due to contri- 
butions from the direct radiation. A more thorough investigation of the differences of the power spectra of the direct, diffuse, and global radiation components is planned for the future.

\section{Summary and conclusions}

A unique data set of global radiation observations has been collected using a dense network of pyranometer stations (Madhavan et al., 2016) during the HOPE Jülich campaign (Macke et al., 2016), and is analyzed in this paper to characterize the small-scale spatiotemporal variability of the global radiation field. The individual time series have been subjected to a multiresolution analysis based on the Haar wavelet following the methodology of Deneke et al. (2009). Characteristic properties have been identified from this analysis for clear-sky, cirrus, overcast, and broken-cloud conditions. Power spectra for the individual time series and the spatial autocorrelation function are presented. A method has been introduced to assess the representativeness of the time series of a point measurement compared to results for a larger area centered around the measurement location. This method allows one to determine the optimal accuracy that can be achieved for the validation of satellite products for a given pixel footprint, or the evaluation of an atmospheric model with a given grid cell resolution. The present study is representative for mid-latitude summer conditions and the results may not be applicable to other regions such as the tropics characterized by local convection, large cumulonimbus clouds, and weaker regional winds.

The most significant findings of this study are summarized as follows:

i. The power spectra of global transmittance exhibit unique characteristics for different prevailing sky conditions associated with the dominant cloud type. For days with broken clouds, the variability of global transmittance is significantly and distinctly higher for all considered frequencies than for other situations, and contains remarkable contributions $\left(1 \% \sim 7 \mathrm{Wm}^{-2}\right)$ even at high frequencies below $1 \mathrm{~min}^{-1}$. This finding is noteworthy as a recommendation for the operation of Baseline Surface Radiation Network (BSRN stations, which only require one to store $1 \mathrm{~min}$ averages (McArthur, 2005), thereby missing significant amounts of variability.

ii. The spatial autocorrelation between stations decreases strongly with increasing frequency. Variations at different points separated by more than $1 \mathrm{~km}$ are completely uncorrelated for higher frequencies above $1 / 3 \mathrm{~min}^{-1}$. The decorrelation lengths decrease linearly with increasing frequency (on a log-log scale) and a distinct dependence on cloud and sky conditions was not observed (see Fig. 7). iii. While the time series of spatially averaged irradiance fields generally resemble the behavior of a point measurement, its power spectrum is strongly attenuated $(96-98 \%$ for $10 \mathrm{~km} \times 10 \mathrm{~km}, 80-90 \%$ for $3.2 \mathrm{~km} \times 3.2 \mathrm{~km}$, and $55-80 \%$ for $1 \mathrm{~km} \times 1 \mathrm{~km})$ at higher frequencies $\left(\sim 1 \mathrm{~min}^{-1}\right)$ and for larger domains. Variations between the spatial average and the point measurement are not correlated at high frequencies. As a consequence, only a small fraction of the highfrequency variability observed in a point measurement can be found in area-averaged (e.g., satellite, model, reanalysis) data.

iv. As a consequence of the previous conclusions, point measurements can deviate strongly from the spatial mean of a surrounding domain. This effect can reach as much as $80 \mathrm{~W} \mathrm{~m}^{-2}$ for a grid box of $10 \mathrm{~km} \times 10 \mathrm{~km}$ corresponding to an averaging time period of $5.25-10.5 \mathrm{~s}$ $\left(D_{13}\right)$ during broken-cloud conditions. For a comparison of time series of a point measurement with that of a spatially averaged value, the power spectrum of the point measurement should be adjusted to match that of the spatial average to ensure best correspondence. A low-pass filter should be applied to remove high frequencies for which the correlation drops below a certain threshold. To determine this threshold, the autocorrelation function has to be known, which, however, depends on the prevailing sky condition.

The methods presented in this paper allow for an explicit treatment of the effects of temporal and spatial averaging on the spatiotemporal variability of global radiation, and can easily be adapted to other geophysical fields. We have applied this methodology to estimate the inherent uncertainty arising from a comparison of two time series with fundamentally different spatial- and temporal-averaging scales, as is commonly done in radiation closure studies, the evaluation of atmospheric models, or satellite products with point measurements. The findings contribute towards a better understanding of the uncertainties in such comparisons.

In future work, we plan to apply these findings towards an assessment of the level of accuracy of satellite-based estimates of shortwave irradiance from Meteosat SEVIRI with ground-based measurements (e.g., Deneke et al., 2008; Greuell et al., 2013), to separate retrieval uncertainties from the inherent uncertainty arising from the limited representativeness of one data set for the other. Based on the results presented here, it is important to explicitly take into account the sky condition including their occurrence frequencies in the validation, as the representativeness error is situation dependent and will therefore influence the validation statistics. A classification of sky conditions based on the observed power spectrum seems promising given the distinct features described above. However, the dependence of power spectra on cloud cover and solar elevation warrants further investigation. Finally, the pyranometer network observations include 
temperature measurements, allowing one to study the correlation of variability in irradiance and temperature.

Due to the spatially distributed nature of the pyranometer network, the present work can also be extended to estimate Lagrangian instead of the Eulerian decorrelation scales, by considering the maxima in the time-lagged cross-correlation of transmittance time series observed at different sites. This time shift can be converted into an estimate of wind speed and direction, and will allow for a separation of changes in radiation resulting from advective changes in clouds, which depend on the wind flow, and from temporal changes in cloud properties, which are independent of current wind speed and direction. Such an analysis will also enable a comparison of spatial and temporal decorrelation scales obtained from geostationary satellite observations (Bley et al., 2016).

Finally, this work can serve as reference for evaluating the representation of clouds including their radiative effects and spatial variability in high-resolution atmospheric models (Heinze et al., 2017), and thereby can contribute towards improved climate predictions. The spatial- and temporalscaling properties of atmospheric transmittance are closely linked to those of the cloud fields. Significant deviations of modeled and observed values can thus be attributed to deficiencies in the simulation of clouds and their interaction with solar radiation (e.g., Harshvardhan et al., 1989; Pincus et al., 2008). Towards this goal, it is also important to clarify to what extent 3-D radiative effects contribute to such deviations. A radiation closure study using reconstructed 3-D cloud distributions based on observations (see, e.g., Fielding et al., 2013) as input to a radiative transfer code (e.g., Macke et al., 1999; Barlakas et al., 2016) could be an essential step towards this, and is planned for the future.

\section{Data availability}

The pyranometer network data used are available upon request to Andreas Macke (macke@tropos.de) or Hartwig Deneke (deneke@tropos.de). The data are archived at the Integrated Climate Data Center. This archive is also referred as the "Standardized Atmospheric Measurement Data" and is accessible at https: //icdc.cen.uni-hamburg.de/index.php?id=samd.E2809D. 


\section{Appendix A: Spatial representativeness of a point time series}

Let $\Psi(\boldsymbol{x}, t)$ represent the time series of a point measurement at point $\boldsymbol{x}$ in the observation domain of interest. The following statistical parameters are defined for this time series:

i. The mean of the time series at $\boldsymbol{x}$ is given by

$$
\overline{\Psi(\boldsymbol{x}, t)}=\mathbb{E}[\Psi(\boldsymbol{x}, t)]
$$

ii. The variance of the time series at $\boldsymbol{x}$ is given by

$$
\operatorname{var}(\Psi(\boldsymbol{x}, t))=\mathbb{E}\left[(\Psi(\boldsymbol{x}, t)-\overline{\Psi(\boldsymbol{x}, t)})^{2}\right] .
$$

iii. The covariance of any two time series at $\boldsymbol{x}_{i}$ and $\boldsymbol{x}_{j}$ is given by

$$
\begin{array}{r}
\operatorname{cov}\left(\Psi\left(x_{i}, t\right), \Psi\left(x_{j}, t\right)\right)=\mathbb{E}\left[\left(\Psi\left(x_{i}, t\right)-\overline{\Psi\left(x_{i}, t\right)}\right)\right. \\
\left.\cdot\left(\Psi\left(x_{j}, t\right)-\overline{\Psi\left(x_{j}, t\right)}\right)\right] .
\end{array}
$$

iv. The autocorrelation $\rho$ between any two time series at $\boldsymbol{x}_{i}$ and $\boldsymbol{x}_{j}$ is given by

$$
\rho\left(\Psi\left(\boldsymbol{x}_{i}, t\right), \Psi\left(\boldsymbol{x}_{j}, t\right)\right)=\frac{\operatorname{cov}\left(\Psi\left(x_{i}, t\right), \Psi\left(\boldsymbol{x}_{j}, t\right)\right)}{\sqrt{\operatorname{var}\left(\Psi\left(\boldsymbol{x}_{i}, t\right)\right) \cdot \operatorname{var}\left(\Psi\left(\boldsymbol{x}_{j}, t\right)\right)}} .
$$

We now assume that the measurement field within the observation domain is statistically homogeneous (i.e., invariant under translation due to the shift in the origin of the coordinate system) and isotropic (i.e., invariant under rotations and reflections of the coordinate system). Consequently, the following properties hold:

a. homogeneity:

$\overline{\Psi(\boldsymbol{x}, t)}=\bar{\Psi}$ for all $\boldsymbol{x}$ and $t$, and $\operatorname{var}(\Psi(\boldsymbol{x}, t))=C$ (i.e., with $C$ constant for all $\boldsymbol{x}$ and $t)$;

b. isotropy:

$\operatorname{cov}\left(\Psi\left(\boldsymbol{x}_{i}, t\right), \Psi\left(\boldsymbol{x}_{j}, t\right)\right)=f\left(d\left(\boldsymbol{x}_{i}, \boldsymbol{x}_{j}\right)\right)$, where $d$ is the distance between the stations, and $f$ is a positive function defined for $d>0$.

By adopting the above assumptions in Eq. (A4), the autocorrelation $\rho$ becomes

$$
\begin{aligned}
\rho\left(\Psi\left(\boldsymbol{x}_{i}, t\right), \Psi\left(\boldsymbol{x}_{j}, t\right)\right) & =\frac{\mathbb{E}\left[\left(\Psi\left(\boldsymbol{x}_{i}, t\right)-\bar{\Psi}\right) \cdot\left(\Psi\left(\boldsymbol{x}_{j}, t\right)-\bar{\Psi}\right)\right]}{\mathbb{E}\left[(\Psi-\bar{\Psi})^{2}\right]} \\
& =\frac{\operatorname{cov}\left(\Psi\left(\boldsymbol{x}_{i}, t\right), \Psi\left(\boldsymbol{x}_{j}, t\right)\right)}{\operatorname{var}(\Psi)} \\
& =\rho\left(d\left(\boldsymbol{x}_{i}, \boldsymbol{x}_{j}\right)\right) .
\end{aligned}
$$

Therefore, the autocorrelation $\rho$ is a function of the distance $d$ between $\boldsymbol{x}_{i}$ and $\boldsymbol{x}_{j}$.

For a spatial area $A$, the area-averaged time series is obtained as

$\Psi_{A}(t)=\frac{1}{A} \iint_{A} \Psi(\boldsymbol{x}, t) \mathrm{d} \boldsymbol{x}$.

The following statistical parameters are found for the areaaveraged time series:

i. The mean of the area-averaged time series is given by

$$
\overline{\Psi_{A}(t)}=\mathbb{E}\left[\Psi_{A}(t)\right]=\bar{\Psi}
$$

ii. The variance of the area-averaged time series is given by

$$
\begin{aligned}
\operatorname{var}\left(\Psi_{A}\right) & =\mathbb{E}\left[\left(\Psi_{A}-\bar{\Psi}\right)^{2}\right] \\
& =\mathbb{E}\left[\frac{1}{A}\left(\iint_{A}\left(\Psi\left(\boldsymbol{x}_{i}, t\right)-\bar{\Psi}\right) \mathrm{d} \boldsymbol{x}_{i}\right)\right. \\
& \left.\cdot \frac{1}{A}\left(\iint_{A}\left(\Psi\left(\boldsymbol{x}_{j}, t\right)-\bar{\Psi}\right) \mathrm{d} \boldsymbol{x}_{j}\right)\right] \\
& =\frac{1}{A^{2}} \cdot \iint_{A} \iint_{A} \mathbb{E}\left[\left(\Psi\left(\boldsymbol{x}_{i}, t\right)-\bar{\Psi}\right)\right. \\
& \left.\cdot\left(\Psi\left(\boldsymbol{x}_{j}, t\right)-\bar{\Psi}\right)\right] \mathrm{d} \boldsymbol{x}_{i} \mathrm{~d} \boldsymbol{x}_{j} \\
& =\frac{1}{A^{2}} \cdot \iint_{A} \iint_{A} \operatorname{cov}\left(\Psi\left(\boldsymbol{x}_{i}, t\right), \Psi\left(\boldsymbol{x}_{j}, t\right)\right) \mathrm{d} \boldsymbol{x}_{i} \mathrm{~d} \boldsymbol{x}_{j} \\
& =\operatorname{var}(\Psi) \cdot\left[\frac{1}{A^{2}} \cdot \iint_{A} \iint_{A} \rho\left(d\left(\boldsymbol{x}_{i}, \boldsymbol{x}_{j}\right)\right) \mathrm{d} \boldsymbol{x}_{i} \mathrm{~d} \boldsymbol{x}_{j}\right] . \quad(\mathrm{A} 8)
\end{aligned}
$$

Therefore, the variance of area-averaged time series is directly proportional to the variance of the time series centered in the observation domain and the domainweighted autocorrelation function $\rho$.

Now, the statistical parameters between the time series centered in the domain and the area-averaged time series for the domain area $A$ are given below: 
i. The covariance of the time series $\Psi$ and the areaaveraged value $\Psi_{A}$ is given by

$$
\begin{aligned}
\operatorname{cov}\left(\Psi, \Psi_{A}\right) & =\mathbb{E}\left[(\Psi-\bar{\Psi}) \cdot\left(\Psi_{A}-\bar{\Psi}\right)\right] \\
& =\mathbb{E}[(\Psi(\boldsymbol{x}, t)-\bar{\Psi}) \\
& \left.\cdot \frac{1}{A}\left(\iint_{A}\left(\Psi\left(\boldsymbol{x}_{i}, t\right)-\bar{\Psi}\right) \mathrm{d} \boldsymbol{x}_{i}\right)\right] \\
& =\frac{1}{A} \cdot \iint_{A} \mathbb{E}[(\Psi(\boldsymbol{x}, t)-\bar{\Psi}) \\
& \left.\cdot\left(\Psi\left(\boldsymbol{x}_{i}, t\right)-\bar{\Psi}\right)\right] \mathrm{d} \boldsymbol{x}_{i} \\
& =\frac{1}{A} \cdot \iint_{A} \operatorname{cov}\left(\Psi(\boldsymbol{x}, t), \Psi\left(\boldsymbol{x}_{i}, t\right)\right) \mathrm{d} \boldsymbol{x}_{i} \\
& =\operatorname{var}(\Psi) \cdot\left[\frac{1}{A} \cdot \iint_{A} \rho\left(d\left(\boldsymbol{x}, \boldsymbol{x}_{i}\right)\right) \mathrm{d} \boldsymbol{x}_{i}\right] .
\end{aligned}
$$

ii. The square of the cross-correlation $\gamma_{A}$ (or explained variance) of the time series centered in the observation domain $\Psi$ and the area-averaged value $\Psi_{A}$ is obtained as the ratio of the square of the corresponding covariance to the product of their individual variances (using Eqs. A8 and A9).

$$
\begin{aligned}
\gamma_{A}^{2} & =\frac{\left[\operatorname{cov}\left(\Psi, \Psi_{A}\right)\right]^{2}}{\operatorname{var}(\Psi) \cdot \operatorname{var}\left(\Psi_{A}\right)} \\
& =\frac{\left[\iint_{A} \rho\left(\mathrm{d}\left(\boldsymbol{x}, \boldsymbol{x}_{i}\right)\right) \mathrm{d} \boldsymbol{x}_{i}\right]^{2}}{\left[\iint_{A} \iint_{A} \rho\left(\mathrm{d}\left(\boldsymbol{x}_{i}, \boldsymbol{x}_{j}\right)\right) \mathrm{d} \boldsymbol{x}_{i} \mathrm{~d} \boldsymbol{x}_{j}\right]}
\end{aligned}
$$

In order to quantify the variance of the difference between the time series $\Psi$ and the area-averaged value $\Psi_{A}$, we assume that the variance of the area-averaged time series is linearly related to the variance of the point time series with an optimal filter, $\alpha_{A}$ (see Eq. A8) defined as follows:

$\operatorname{var}\left(\Psi_{A}\right)=\alpha_{A} \cdot \operatorname{var}(\Psi)$.

Now, the variance of the difference between the point time series $\Psi$ and the area-averaged time series $\Psi_{A}$ (i.e., the unexplained variance) is given by

$$
\begin{aligned}
\operatorname{var}\left(\Psi-\Psi_{A}\right) & =\operatorname{var}\left(\Psi_{A}\right)+\operatorname{var}(\Psi)-2 \cdot \operatorname{cov}\left(\Psi_{A}, \Psi\right) \\
& =\operatorname{var}\left(\Psi_{A}\right)+\operatorname{var}(\Psi) \\
& -2 \cdot \gamma_{A} \cdot \sqrt{\operatorname{var}\left(\Psi_{A}\right) \cdot \operatorname{var}(\Psi)} \\
& =\left(\alpha_{A}+1\right) \cdot \operatorname{var}(\Psi)-2 \cdot \gamma_{A} \cdot \sqrt{\alpha_{A}} \cdot \operatorname{var}(\Psi) \\
& =\left[\alpha_{A}+1-2 \cdot \gamma_{A} \cdot \sqrt{\alpha_{A}}\right] \cdot \operatorname{var}(\Psi) .
\end{aligned}
$$

Expressing Eq. (A12) in terms of the standard deviation, the area-averaging error $\delta$ between the point time series $\Psi$ and area-averaged time series $\Psi_{A}$ can be obtained as follows:

$\delta\left(\Psi-\Psi_{A}\right)=\sqrt{\left(\alpha_{A}+1-2 \cdot \gamma_{A} \cdot \sqrt{\alpha_{A}}\right)} \cdot \delta(\Psi)$.
Alternately, we define a damped time series $\Psi^{\prime}$ as the representative variability at a single station and as given below:

$\Psi^{\prime}=\sqrt{\alpha_{A}} \cdot(\Psi-\bar{\Psi})+\bar{\Psi}$.

The above Eq. (A14) implies that

$\operatorname{var}\left(\Psi^{\prime}\right)=\alpha_{A} \cdot \operatorname{var}(\Psi)$.

The variance of the difference between the point time series $\Psi^{\prime}$ and the area-averaged time series $\Psi_{A}$ is then given by

$$
\begin{aligned}
\operatorname{var}\left(\Psi^{\prime}-\Psi_{A}\right) & =\operatorname{var}\left(\Psi_{A}\right)+\operatorname{var}\left(\Psi^{\prime}\right)-2 \cdot \operatorname{cov}\left(\Psi_{A}, \Psi^{\prime}\right) \\
& =\alpha_{A} \cdot \operatorname{var}(\Psi)+\alpha_{A} \cdot \operatorname{var}(\Psi) \\
& -2 \cdot \gamma_{A} \sqrt{\operatorname{var}\left(\Psi_{A}\right) \cdot \operatorname{var}\left(\Psi^{\prime}\right)} \\
& =2 \cdot \alpha_{A} \cdot \operatorname{var}(\Psi) \\
& -2 \cdot \gamma_{A} \sqrt{\alpha_{A} \cdot \operatorname{var}(\Psi) \cdot \operatorname{var}\left(\Psi^{\prime}\right)} \\
& =2 \cdot \alpha_{A} \cdot\left(1-\gamma_{A}\right) \cdot \operatorname{var}(\Psi)
\end{aligned}
$$

Expressing the Eq. (A16) in terms of the standard deviation, the area-averaging error $\delta$ between the point time series $\Psi$ and area-averaged time series $\Psi_{A}$ can be obtained as follows:

$\delta\left(\Psi^{\prime}-\Psi_{A}\right)=\sqrt{2 \cdot \alpha_{A}-2 \cdot \alpha_{A} \cdot \gamma_{A}} \cdot \delta(\Psi)$.

Comparing Eqs. (A13) and (A17), we find $\delta\left(\Psi^{\prime}-\Psi_{A}\right)<$ $\delta\left(\Psi-\Psi_{A}\right)$ as $\gamma_{A} \leq 1$. 
Competing interests. The authors declare that they have no conflict of interest.

Acknowledgements. The authors acknowledge essential technical support from the TROPOS mechanics and electronics workshops in designing and building the autonomous pyranometer, especially Cornelia Kurze and Hartmut Haudek. Many thanks to all the private landowners for their support. We are grateful to the Research Center Jülich (FZJ) for their valuable logistic support in setting up and maintaining the instruments. The first author acknowledges the funding support of the Federal Ministry of Education and Research (BMBF), Germany, as part of the $\mathrm{HD}(\mathrm{CP})^{2}$ project (grant no. 01LK1212C). We thank our colleague Fabian Senf, and Piet Stammes from KNMI, the Netherlands, for their valuable comments and suggestions during various stages of this manuscript. We also thank John Kalisch, Sebastian Bley, Daniel Merk, Felix Dietzsch, Timo Hanschmann, Michael Eickmeier, Anja Hünerbein, Felix Peintnet, Alexander Graf (FZJ), and Ronny Badeke for extending their support during the HOPE campaigns. Daily TSI time-azimuth data were provided by Jan H. Schween from the group of Susanne Crewell at the University of Cologne, Köln. We appreciate the support provided by Alexander Los and Kees Hogendijk from EKO Instruments, the Netherlands.

Edited by: S. Buehler

Reviewed by: M. Nunez and one anonymous referee

\section{References}

Baker, M. B.: Cloud microphysics and climate, Science, 276, 10721078, doi:10.1126/science.276.5315.1072, 1997.

Baker, M. B. and Peter, T.: Small-scale cloud processes and climate, Nature, 451, 299-300, doi:10.1038/nature06594, 2008.

Barker, H. W. and $\mathrm{Li}, \mathrm{Z}$.: Interpreting shortwave albedotransmittance plots: True or apparent anomalous absorption?, Geophys. Res. Lett., 24, 2023-2027, doi:10.1029/97GL02019, 1997.

Barker, H. W., Curtis, T. J., Leontieva, E., and Stamnes, K.: Optical depth of overcast cloud across Canada: estimates based on surface pyranometer and satellite measurements, J. Climate, 11, 2980-2994, doi:10.1175/15200442(1998)011<2980:ODOOCA>2.0.CO;2, 1998.

Barlakas, V., Macke, A., and Wendisch, M.: SPARTA - Solver for Polarized Atmospheric Radiative Transfer Applications: Introduction and application to Saharan dust fields, J. Quant. Spectrosc. Ra., 178, 77-92, doi:10.1016/j.jqsrt.2016.02.019, 2016.

Barnett, T. P., Ritchie, J., Foat, J., and Stokes, G.: On the Space-Time Scales of the Surface Solar Radiation Field, J. Climate, 11, 88-96, doi:10.1175/15200442(1998)011<0088:OTSTSO>2.0.CO;2, 1998.

Beals, M. J., Fugal, J. P., Shaw, R. A., Lu, J., Spuler, S. M., and Stith, J. L.: Holographic measurements of inhomogeneous cloud mixing at the centimeter scale, Science, 350, 87-90, doi:10.1126/science.aab0751, 2015.

Boers, R., Spinhirne, J. D., and Hart, W. D.: Lidar observations of the fine-scale variability of marine stratocumulus clouds, J. Appl. Meteorol., 27, 797-810, doi:10.1175/15200450(1988)027<0797:LOOTFS>2.0.CO;2, 1988.

Boers, R., van Lammeren, A., and Feijt, A.: Accuracy of cloud optical depth retrievals from ground based pyranometers, J. Atmos. Ocean. Techn., 17, 916-927, doi:10.1175/15200426(2000)017<0916:AOCODR>2.0.CO;2, 2000.

Bley, S., Deneke, H., and Senf, F.: Meteosat-Based Characterization of the Spatiotemporal Evolution of Warm Convective Cloud Fields over Central Europe, J. Appl. Meteorol. Clim., 55, 21812195, doi:10.1175/JAMC-D-15-0335.1, 2016.

Boucher, O., Randell, D., Artaxo, P., Bretherton, C., Feingold, G., Forster, P., Kerminen, V.-M., Kondo, Y., Liao, H., Lohmann, U., Rasch, P., Satheesh, S. K., Sherwood, S., Stevens, B., and Zhang, X. Y.: Clouds and Aerosols Supplementary Material, in: Climate Change 2013: The Physical Science Basis, Contribution of Working Group I to the Fifth Assessment Report of the Intergovernmental Panel on Climate Change, edited by: Stocker, T. F., Qin, D., Plattner, G.-K., Tignor, M., Allen, S. K., Boschung, J., Nauels, A., Xia, Y., Bex, Y., and Midgley, P. M., available at: http: //www.climatechange2013.org/report/full-report/ (last access: 8 February 2017), 2013.

Cahalan, R. F. and Snider, J. B.: Marine stratocumulus structure, Remote Sens. Environ., 28, 95-107, doi:10.1016/00344257(89)90108-9, 1989.

Cahalan, R. F., Ridgway, W., Wiscombe, W. J., and Bell, T. L.: The Albedo of Fractal Stratocumulus Clouds, J. Atmos. Sci., 51, 2434-2455, doi:10.1175/15200469(1994)051<2434:TAOFSC>2.0.CO;2, 1994.

Davis, A., Marshak, A., Gerber, H., and Wiscombe, J. W.: Horizontal structure of marine boundary layer clouds from centimeter to kilometer scales, J. Geophys. Res., 104, 6123-6144, doi:10.1029/1998JD200078, 1999.

Deneke, H., Feijt, A., Lammeren, A., and Simmer, C.: Validation of a Physical Retrieval Scheme of Solar Surface Irradiances from Narrowband Satellite Radiances, J. Appl. Meteorol., 44, 14531466, doi:10.1175/JAM2290.1, 2005.

Deneke, H., Roebeling, R., and Feijt, A.: Estimating surface solar irradiance from METEOSAT SEVIRI derived cloud properties, Remote Sens. Environ., 112, 3131-3141, doi:10.1016/j.rse.2008.03.012, 2008.

Deneke, H. M., Knap, W. H., and Simmer, C.: Multiresolution analysis of the temporal variance and correlation of transmittance and reflectance of an atmospheric column, J. Geophys. Res., 114, D17206 doi:10.1029/2008JD011680, 2009.

Deneke, H. M. and Roebeling, R. A.: Downscaling of METEOSAT SEVIRI 0.6 and $0.8 \mu \mathrm{m}$ channel radiances utilizing the highresolution visible channel, Atmos. Chem. Phys., 10, 9761-9772, doi:10.5194/acp-10-9761-2010, 2010.

Dobbie, S. and Jonas, P.: Radiative influences on the structure and lifetime of cirrus clouds, Q. J. Roy. Meteorol. Soc., 127, 26632682, doi:10.1002/qj.49712757808, 2001.

Duchon, C. and O'Malley, M.: Estimating cloud type from pyranometer observations, J. Appl. Meteorol., 38, 132-141, doi:10.1175/1520-0450(1999)038<0132:ECTFPO>2.0.CO;2, 1999.

Eaton, B., Gregory, J., Drach, B., Taylor, K., Hankin, S., Caron, J., Signell, R., Bentley, P., Rappa, G., Höck, H., Pamment, A., and Juckes, M.: NetCDF Climate and Forecast (CF) Metadata Conventions, Version 1.6, available at: http://cfconventions.org/ 
cf-conventions/v1.6.0/cf-conventions.pdf (last access: 8 February 2017), 2011.

Enriquez-Alonso, A., Sanchez-Lorenzo, A., Calbó, J., González, J. A., and Norris, J.: Cloud cover climatologies in the Mediterranean obtained from Satellites, Surface observations, Reanalysis, and CMIP5 simulations: Validation and Future Scenarios, Clim. Dynam., 47, 249-269, doi:10.1007/s00382015-2834-4, 2016.

Few, S.: Time on the horizon, Perceptual Edge, available at: http://www.perceptualedge.com/articles/visual_business_ intelligence/time_on_the_horizon.pdf (last access: 8 February 2017), 2008.

Fielding, M. D., Chiu, J. C., Hogan, R. J., and Feingold, G.: 3-D cloud reconstructions: Evaluation of scanning radar scan strategy with a view to surface shortwave radiation closure, J. Geophys. Res.-Atmos., 118, 9153-9167, doi:10.1002/jgrd.50614, 2013.

Gandin, L. S.: Optimal Averaging of Meteorological Fields, Office note 397, National Oceanographic and Atmospheric Administration, National Meteorological Center, USA, available at: http: //www.lib.ncep.noaa.gov/ncepofficenotes/files/014089EE.pdf (last access: 8 February 2017), 1993.

Gerber, H., Jensen, J. B., Davis, A. B., Marshak, A., and Wiscombe, W. J.: Spectral density of cloud liquid water content at high frequencies, J. Atmos. Sci., 58, 497-503, doi:10.1175/15200469(2001)058<0497:SDOCLW>2.0.CO;2, 2001.

Greuell, W. and Roebeling, R. A.: Toward a standard procedure for validation of satellite-derived cloud liquid water path: A study with SEVIRI data, J. Appl. Meteorol. Cim., 48, 1575-1590, doi:10.1175/2009JAMC2112.1, 2009.

Greuell, W., Meirink, J. F., and Wang, P.: Retrieval and validation of global, direct, and diffuse irradiance derived from SEVIRI satellite observations, J. Geophys. Res.-Atmos., 118, 2340-2361, doi:10.1002/jgrd.50194, 2013.

Grosmann, A. and Morlet, J.: Decomposition of hardy functions into square integrable wavelet of constant shape, SIAM J. Math. Anal., 723-736, doi:10.1137/0515056, 1984.

Haar, A.: Zur Theorie der orthogonalen Funktionensysteme (in German), Math. Ann., 69, 331-371, doi:10.1007/BF01456326, 1910.

Harshvardhan, Randall, D. A., Corsetti, T. G., and Dazlich, D. A.: Earth radiation budget and cloudiness simulations with a general circulation model, J. Atmos. Sci., 46, 1922-1942, available at: http://kiwi.atmos.colostate.edu/pubs/Harshvardhanetal-1989. pdf (last access: 8 February 2017), 1989.

Heer, J., Kong, N. and Agarwala, M.: Sizing the horizon: The effects of chart size and layering on the graphical perception of time series visualization, in ACM Human Factors in Computing (CHI), Boston, MA, USA, available at: http://vis.berkeley.edu/ papers/horizon/2009-TimeSeries-CHI.pdf (last access: 8 February 2017), 2009.

Heinze, R., Dipankar, A., Carbajal-Henken, C., Moseley, C., Sourdeval, O., Trömel, S., Xie, X., Adamidis, P., Ament, F., Baars, H., Barthlott, C., Behrendt, A., Blahak, U., Bley, S., Brdar, S., Brück, M., Crewell, S., Deneke, H., Di Girolamo, P., Evaristo, R., Fischer, J., Frank, C., Friederichs, P., Göcke, T., Gorges, K., Hande, L., Hanke, M., Hansen, A., Hege, H.-C., Hoose, C., Jahns, T., Kalthoff, N., Klocke, D., Kneifel, S., Knippertz, P., Kuhn, A., van Laar, T., Macke, A., Maurer, V., Meyer, C. I., Muppa, S. K., Neggers, R., Orlandi, E., Pantil- lon, F., Pospichal, B., Röber, N., Scheck, L., Seifert, A., Senf, F., Siligam, P., Simmer, C., Steinke, S., Stevens, B., Wapler, K., Weniger, M., Wulfmeyer, V., Zängl, G., Zhang, D., and Quaas, J.: Large-eddy simulations over Germany using ICON: A comprehensive evaluation, Q. J. Roy. Meteorol. Soc., 143, 69-100, doi:10.1002/qj.2947, 2017.

Henderson-Sellers, A., Seze, G., Drake, F., and Desbois, M.: Surface and satellite cloudiness for Europe in 1983, J. Geophys. Res., 92, 4019-4033, doi:10.1029/JD092iD04p04019, 1987.

Hinkelman, L. M., Evans, K. F., Clothiaux, E. E., Ackerman, T. P., and Stackhouse, P. W.: The Effect of Cumulus Cloud Field Anisotropy on Domain-Averaged Solar Fluxes and Atmospheric Heating Rates, J. Atmos. Sci., 64, 3499-3520, doi:10.1175/JAS4032.1, 2007.

Hinkelman, L. M.: Differences between along-wind and cross-wind solar irradiance variability on small spatial scales, Sol. Energy, 88, 192-203, doi:10.1016/j.solener.2012.11.011, 2013.

Hoff, T. E. and Perez, R.: Modeling PV fleet output variability, Sol. Energy, 86, 2177-2189, doi:10.1016/j.solener.2011.11.005, 2012.

Horvath, A. and Davies, R.: Anisotropy of water cloud reflectance: A comparison of measurements and 1-D theory, Geophys. Res. Lett., 31, L01102, doi:10.1029/2003GL018386, 2004.

Horvath, A., Seethala, C., and Deneke, H.: View angle dependence of MODIS liquid water path retrievals in warm oceanic clouds, J. Geophys. Res., 119, 8304-8328, doi:10.1002/2013JD021355, 2014.

Kagan, R. L.: Averaging meteorological fields, Gidrometeoizdat, Leiningrad, available at: http://trove.nla.gov.au/work/23925149 (last access: 8 February 2017), 1979 (in Russian).

King, D. L. and Myers, D. R.: Silicon-photodiode pyranometers: Operational characteristics, historical experiences, and new calibration procedures, Conference Record of the IEEE Photovoltaic Specialists Conference, 1-6, doi:10.1109/PVSC.1997.654323, 1997.

King, W. D., Maher, C. T., and Hepburn, G. A.: Further performance tests on the CSIRO Liquid Water Probe, J. Appl. Meteorol., 20, 195-202, doi:10.1175/15200450(1981)020<0195:FPTOTC>2.0.CO;2, 1981.

Kopp, G. and Lean, J. L.: A new, lower value of total solar irradiance: evidence and climate significance, Geophys. Res. Lett., 38, L01706, doi:10.1029/2010GL045777, 2011.

Koren, I., Oreopoulos, L., Feingold, G., Remer, L. A., and Altaratz, O.: How small is a small cloud?, Atmos. Chem. Phys., 8, 38553864, doi:10.5194/acp-8-3855-2008, 2008.

Lensky, I. M. and Rosenfeld, D.: Clouds-Aerosols-Precipitation Satellite Analysis Tool (CAPSAT), Atmos. Chem. Phys., 8, 6739-6753, doi:10.5194/acp-8-6739-2008, 2008.

Lohmann, G. M., Monahan, A. H., and Heinemann, D.: Local shortterm variability in solar irradiance, Atmos. Chem. Phys., 16, 6365-6379, doi:10.5194/acp-16-6365-2016, 2016.

Long, C. and Ackerman, T.: Surface measurements of solar irradiance: A study of the spatial correlation between simultaneous measurements at separate sites, J. Appl. Meteorol., 34, 1039-1046, doi:10.1175/15200450(1995)034<1039:SMOSIA>2.0.CO;2, 1995.

Löhnert, U., Schween, J. H., Acquistapace, C., Ebell, K., Maahn, M., Barreraverdejo, M., Hirsikko, A., Bohn, B., Knaps, A., O'Connor, E., Simmer, C., Wahner, A., and 
Crewell, S.: JOYCE: Jülich Observatory for Cloud Evolution, B. Am. Meteorol. Soc., 96, 1157-1174, doi:10.1175/BAMS-D-1400105.1, 2014.

Macke, A., Mitchell, D. L., and Bremen, L. V.: Monte-Carlo radiative transfer calculations for inhomogeneous mixed phase clouds, Phys. Chem. Earth Pt. B, 24, 237-241, doi:10.1016/S14641909(98)00044-6, 1999.

Macke, A., Seifert, P., Baars, H., Beekmans, C., Behrendt, A., Bohn, B., Bühl, J., Crewell, S., Damian, T., Deneke, H., Düsing, S., Foth, A., Di Girolamo, P., Haman, E., Heinze, R., Kalisch, J., Kalthoff, N., Kinne, S., Kohler, M., Löhnert, U., Madhavan, B. L., Maurer, V., Muppa, S. K., Schween, J., Serikov, I., Siebert, H., Simmer, C., Späthe, F., Steinke, S., Träumner, K., Wehner, B., Wieser, A., Wulfmeyer, V., and Xie, X.: The $H D(C P)^{2}$ Observational Prototype Experiment HOPE - An Overview, Atmos. Chem. Phys. Discuss., doi:10.5194/acp-2016-990, in review, 2016.

Madhavan, B. L., He, Y., Wu, Y., Gross, B., Moshary, F., and Ahmed, S.: Development of a Ground Based Remote Sensing Approach for Direct Evaluation of Aerosol-Cloud Interaction, Atmosphere, 3, 468-494, doi:10.3390/atmos3040468, 2012.

Madhavan, B. L., Kalisch, J., and Macke, A.: Shortwave surface radiation network for observing small-scale cloud inhomogeneity fields, Atmos. Meas. Tech., 9, 1153-1166, doi:10.5194/amt-91153-2016, 2016.

McArthur, L. J. B.: World Climate Research Program - Baseline Surface Radiation Network (BSRN), Operations Manual Version 2.1, WCRP-121, WMO/TD-No. 1274, available at: http://epic. awi.de/30644/ (last access: 8 February 2017), 2005.

Michalsky, J., Dutton, E., Rubes, M., Nelson, D., Stoffel, T., Wesley, M., Splitt, M., and DeLuisi, J.: Optimal measurement of surface shortwave irradiance using current instrumentation, J. Atmos. Ocean. Tech., 16, 55-69, doi:10.1175/15200426(1999)016<0055:OMOSSI>2.0.CO;2, 1999.

Norris, J. R. and Evan, A. T.: Empirical removal of artifacts from the ISCCP and PATMOS-x satellite cloud records, J. Atmos. Ocean Tech, 32, 691-702, doi:10.1175/JTECH-D-14-00058.1, 2015.

Núñez, M., Fienberg, K., and Kuchinke, C.: Temporal Structure of the Solar Radiation Field in Cloudy Conditions: Are Retrievals of Hourly Averages from Space Possible?, J. Appl. Meteorol., 44, 167-178, doi:10.1175/JAM-2196.1, 2005.

Núñez, M., Marín-Fernandez, M. J., Serrano, D., Utrillas, M. P., Fienberg, K., and Martínez-Lozano, J. A.: Sensitivity of UV enhancement to broken liquid water clouds: a Monte Carlo approach as applied to Valencia, Spain, J. Geophys. Res., 121, 949964, doi:10.1002/2015JD024000, 2016.

Ohmura, A., Dutton, E. G., Forgan, B., Fröhlich, C., Gilgen, H., Hegner, H., Heimo, A., König-Langlo, G., McArthur, B., Müller, G., Philipona, R., Pinker, R., Whitlock, C. H., Dehne, K., and Wild, M.: Baseline Surface Radiation Network (BSRN/WCRP): new precision radiometry for climate research, B. Am. Meteorol. Soc., 79, 2115-2136, doi:10.1175/15200477(1998)079<2115:BSRNBW>2.0.CO;2, 1998.

Oreopoulos, L., Marshak, A., Cahalan, R. F., and Wen G.: Cloud three-dimensional effects evidenced in Landsat spatial power spectra and autocorrelation functions, J. Geophys. Res., 105, 14777-14788, doi:10.1029/2000JD900153, 2000.

Percival, D.: On estimation of the wavelet variance, Biometrika, 82, 619-631, doi:10.1093/biomet/82.3.619, 1995.
Percival, D. and Walden, A. T.: Wavelet methods for time series analysis, Cambridge University Press, 2005.

Perpiñán, O., Marcos, J., and Lorenzo, E.: Electrical power fluctuations in a network of DC/AC inverters in a large PV plant: Relationship between correlation, distance and time scale, Sol. Energy, 88, 227-241, doi:10.1016/j.solener.2012.12.004, 2013.

Pincus, R., McFarlane, S. A., and Klein, S. A.: Albedo bias and the horizontal variability of clouds in subtropical marine boundary layers: Observations from ships and satellites, J. Geophys. Res., 104, 6183-6191, doi:10.1029/1998JD200125, 1999.

Pincus, R., Batstone, C. P., Hofmann, R. J. P., Taylor, K. E., and Glecker, P. J.: Evaluating the present-day simulation of clouds, precipitation, and radiation in climate models, J. Geophys. Res., 113, D14209, doi:10.1029/2007JD009334, 2008.

Roebeling, R. A., Deneke, H. M., and Feijt, A. J.: Validation of cloud liquid water path retrievals from SEVIRI using one year of CloudNET observations, J. Appl. Meteorol., 47, 206-222, doi:10.1175/2007JAMC1661.1, 2008.

Roebeling, R. A. and Holleman, I.: SEVIRI rainfall retrieval and validation using weather radar observations, J. Geophys. Res., 114, D21202, doi:10.1029/2009JD012102, 2009.

Robles Gil, S.: The socio-economic benefits of climatological services to the renewable energy sector, WMO Bulletin, Geneva, Switzerland, Tech. Rep., 56, 40-45, available at: http://www.wmo.int/pages/prog/ wcp/ccl/opace/opace4/meetings/documents/E2Socio_

EconomicBenefitsofcstoRenewableEnergySector_Robles-Gil. pdf (last access: 1 August 2016), 2007.

Schade, N. H., Macke, A., Sandmann, H., and Stick, C.: Enhanced solar global irradiance during cloudy sky conditions, Meteorol. Z., 16, 295-303, doi:10.1127/0941-2948/2007/0206, 2007.

Scheirer, R. and Macke, A.: Cloud inhomogeneity and broadband solar fluxes, J. Geophys. Res., 108, 4599, doi:10.1029/2002JD003321, 2003.

Schewski, M. and Macke, A.: Correlation between domain averaged cloud properties, and solar radiative fluxes for three-dimensional inhomogenous mixed phase clouds, Meteorol. Z., 12, 293-299, doi:10.1127/0941-2948/2003/0012-0293, 2003.

Schmidt, K. S., Venema, V., Giuseppe, F. D., Scheirer, R., Wendisch, M., and Pilewskie, P.: Reproducing cloud microphysical and irradiance measurements using three 3-D cloud generators, Q. J. Roy. Meteorol. Soc., 133, 765-780, doi:10.1002/qj.53, 2007.

Schutgens, N. A. and Roebeling, R. A.: Validating the Validation: The Influence of Liquid Water Distribution in Clouds on the Intercomparison of Satellite and Surface Observations, J. Atmos. Ocean. Technol., 26, 1457-1474, doi:10.1175/2009JTECHA1226.1, 2009

Slobodda, J., Hünerbein, A., Lindstrot, R., Preusker, R., Ebell, K., and Fischer, J.: Multichannel analysis of correlation length of SEVIRI images around ground-based cloud observatories to determine their representativeness, Atmos. Meas. Tech., 8, 567578, doi:10.5194/amt-8-567-2015, 2015.

Stensrud, D. J.: Parameterization Schemes: Keys to Understanding Numerical Weather Prediction Models, Cambridge University Press, 480 pp., 2009.

Stubenrauch, C. J., Rossow, W. B., Kinne, S., Ackerman, S., Cesana, G., Chepfer, H., Di Girolamo, L., Getzewich, B., Guignard, A., Heidinger, A., Maddux, B. C., Menzel, W. P., Min- 
nis, P., Pearl, C., Platnik, S., Poulsen, C., Riedi, J., Sun-Mack, S., Walther, A., Winker, D., Zeng, S., and Zhao, G.: Assessment of Global Cloud Datasets from Satellites: Project and Database initiated by the GEWEX Radiation Panel, B. Am. Meteorol. Soc., 94, 1031-1049, doi:10.1175/BAMS-D-12-00117.1, 2013.

Trenberth, K. E., Fasullo, J. T., and Kiehl, J.: Earth's Global Energy Budget, B. Am. Meteorol. Soc., 311-323, doi:10.1175/2008BAMS2634.1, 2009.

van den Hurk, B., Bastiaanssen, W., Pelgrum, H., and van Meijgaard, E.: A new methodology for initialization of soil moisture fields in numerical weather prediction models using METEOSAT and NOAA data, J. Appl. Meteorol., 36, 1271-1283, doi:10.1175/15200450(1997)036<1271\%3AANMFAO>2.0.CO\%3B2, 1997.

Venema, V., Meyer, S., Gracía, S. G., Kniffka, A., Simmer, C., Crewell, S., Löhnert, U., Trautmann, T., and Macke, A.: Surrogate cloud fields generated with the iterative amplitude Fourier transform algorithm, Tellus, 58A, 104-120, doi:10.1111/j.16000870.2006.00160.x, 2006.

Vinnikov, K. Y., Groisman, P. Y., and Lugina, K. M.: Empirical Data on Contemporary Global Climate Changes (Temperature and Precipitation), J. Climate, 3, 662-677 doi:10.1175/15200442(1990)003<0662:EDOCGC>2.0.CO;2, 1990.
Vinnikov, K. Y., Robock, A., Qiu, S., and Entin, J. K.: Optimal design of surface networks for observation of soil moisture, J. Geophys. Res., 104, 19743-19749, doi:10.1029/1999JD900060, 1999.

Whitcher, B., Guttorp, P., and Percival, D. B.: Wavelet analyses of covariance with application to atmospheric time series, J. Geophys. Res., 105, 14941-14962, doi:10.1029/2000JD900110, 2000.

WMO-No. 8: Guide to Meteorological Instruments and Methods of Observation, Seventh Edition, Chapter 7, Annex 7.D, World Meteorological Organization, Geneva, Switzerland, available at: https://www.wmo.int/pages/prog/gcos/documents/ gruanmanuals/CIMO/CIMO_Guide-7th_Edition-2008.pdf (last access: 8 February 2017), 2008.

Zinner, T. and Mayer, B.: Remote sensing of stratocumulus clouds: Uncertainties and biases due to inhomogeneity, J. Geophys. Res., 111, D14209, doi:10.1029/2005JD006955, 2006. 